\title{
The role of F-18-fluorothymidine PET in oncology
}

\author{
Francesco Bertagna • Giorgio Biasiotto • \\ Raffaele Giubbini
}

Received: 2 October 2012/ Accepted: 25 February 2013/Published online: 28 March 2013

(C) Italian Association of Nuclear Medicine and Molecular Imaging 2013

\begin{abstract}
F}\right]\right.$ Fluoro)-fluorothymidine, $\left({ }^{18} \mathrm{~F}\right.$ FLT) is a fluorinated tracer which has been proposed as an imaging biomarker of cell proliferation. The aim of this review is to provide an overall evaluation and description of the diagnostic role of ${ }^{18} \mathrm{~F}$-FLT PET or PET/CT in oncology imaging and clinical practice. A comprehensive computer literature search of the PubMed/Medline databases revealed 371 articles. After reviewing the titles and abstracts, 285 articles were excluded, mainly because the reported data were not within the field of interest; 86 articles were selected. The overall assessment of the published studies showed marked heterogeneity both of the tumors analyzed and of the reasons for evaluation (diagnosis, staging, restaging, and therapy response evaluation). The tumor or organ most frequently analyzed was the lung, in 19 studies; the digestive tract was analyzed in 17 papers, brain tumors in 15, head and neck tumors in nine, myeloproliferative/lymphoproliferative diseases in nine, and breast cancer in six. Eleven studies dealt with the other forms of tumor (including melanomas, sarcomas, ovarian cancer, uterine cancer, germ cell tumors, and neuroendocrine tumors). Although no high-quality evidence could be derived on the role of ${ }^{18}$ F-FLT PET in oncology imaging, because of the extreme heterogeneity between the studies (with regard to the tumors evaluated, the reasons for performing the evaluations, and the devices and methodologies
\end{abstract}

F. Bertagna $(\varangle) \cdot$ R. Giubbini

Nuclear Medicine, University of Brescia and Spedali Civili di

Brescia, P.le Spedali Civili, 1, 25123 Brescia, Italy

e-mail: francesco.bertagna@spedalicivili.brescia.it;

francesco.bertagna@med.unibs.it

G. Biasiotto

Biomedical Technology Department, University of Brescia, Brescia, Italy used), the limited number of studies per tumor type, and the very low number of patients enrolled in each study, these preliminary results seem to indicate a promising role for this tracer in oncology imaging, especially in therapy response evaluation and in brain tumors; it is also associated with a lower rate of false-positive results due to inflammation. Further studies are needed to confirm these preliminary results, and larger trials are desirable to establish the definitive diagnostic role of ${ }^{18} \mathrm{~F}$-FLT in oncological clinical practice, considering its usefulness in relation to and in comparison with the already well-established $2-\left(\left[{ }^{18} \mathrm{~F}\right] \mathrm{Flu}\right.$ oro)-2-deoxy-D-glucose, ( $\left.{ }^{18} \mathrm{~F}-\mathrm{FDG}\right)$, its importance in terms of cost-effectiveness, and its correct position in the diagnostic flow-chart for each tumor type.

Keywords 3'-Deoxy-3'-18-fluorothymidine $\cdot$ Positron emission tomography/computed tomography - Oncology · ${ }^{18}$ F-labeled tracer

\section{Introduction}

The role of positron emission tomography/computed tomography (PET/CT) in oncology imaging is rapidly expanding in clinical practice worldwide, due to increased clinical demand driven by greater availability of cyclotrons and automated chemistry synthesis modules for the production of radiopharmaceuticals. The added value of metabolic imaging over conventional imaging lies in its ability to evaluate specific metabolic pathways, providing semiquantitative measurements of tumor biology; nuclear medicine physicians and referring clinicians are living in wait for the introduction of new PET radiopharmaceuticals for routine clinical use. Most imaging studies are performed using ${ }^{18} \mathrm{~F}$-FDG PET, which is a highly sensitive 
and quite specific tracer for many entities. Despite the availability of numerous new tracers such as Sodium $\left[{ }^{18} \mathrm{~F}\right]$ Fluoride ${ }^{18} \mathrm{~F}$-Fluoride, 3,4-dihydroxy-6-( $\left[{ }^{18} \mathrm{~F}\right]$ Fluoro)-Lphenylalanine, $\left({ }^{18} \mathrm{~F}\right.$-DOPA), $1-\left[{ }^{11} \mathrm{C}\right]$ acetate, $\left({ }^{11} \mathrm{C}\right.$-acetate $)$, $\mathrm{N}-\left[{ }^{11} \mathrm{C}\right]$ methyl-choline, $\left({ }^{11} \mathrm{C}\right.$-choline $)$, and $\mathrm{N}-\left[{ }^{18} \mathrm{~F}\right]$ methylcholine, ${ }^{18} \mathrm{~F}$-FDG remains difficult to beat. However, because ${ }^{18} \mathrm{~F}$-FDG is not without its limitations, efforts have been made to study new tracers such as $3^{\prime}$-deoxy-3'-18-fluorothymidine $\left({ }^{18} \mathrm{~F}\right.$-FLT $)$. Cell proliferation is a pivotal aspect of tumor development and growth and is therefore a main target of cancer imaging. Cell proliferation can be assessed by a number of in vitro assays, which require tissue from biopsies; understanding of the molecular biology of cancer has conventionally been based on assays of tissue or blood samples. However, biopsies can be difficult to obtain, and they may not be representative of the proliferative activity of the whole tumor. As a consequence, imaging biomarkers have been explored as surrogates for these measurements, offering two main advantages: (1) whole-tumor and whole-body evaluation and (2) a non-invasive assessment. Even though ${ }^{18} \mathrm{~F}-\mathrm{FDG}$ has a wide field of application, some malignant tumors such as prostate cancer, neuroendocrine tumors, and hepatic tumors often fail to show significant uptake and may therefore go undetected. Moreover, ${ }^{18}$ F-FDG presents two major drawbacks in oncology: it is not useful for evaluating malignancies in tissues with physiologically high glycolytic metabolism such as central nervous system tissues, and it cannot distinguish between inflammation and cancer, as both are characterized by increased glucose consumption. ${ }^{18} \mathrm{~F}$-FLT is a fluorinated tracer which has been proposed as an imaging biomarker of cell proliferation; in fact, during the $\mathrm{S}$ phase of the cell cycle, ${ }^{18} \mathrm{~F}$-FLT is phosphorylated by thymidinekinase-1 (TK-1) and trapped inside the cell, but not incorporated into the DNA, and thus provides an indirect measure of proliferation [1]. ${ }^{18} \mathrm{~F}$-FLT was originally produced after investigators discovered the anti-HIV properties of azidothymidine. In the initial phase I trial in patients with acquired immunodeficiency syndrome (AIDS), 3'-deoxy-3'-fluorothymidine (alovudine) was found to have higher toxicity at clinically useful doses [2]. These pharmacologic studies of unlabeled FLT, however, demonstrated that it can safely be given at the tracer doses used in PET. ${ }^{18} \mathrm{~F}$-FLT is transported into the cell in a manner similar to thymidine and then phosphorylated to ${ }^{18}$ F-FLT- 5 -monophosphate and then further phosphorylated to FLT-triphosphate by the enzyme thymidylate kinase. FLT phosphates, however, are impermeable to the cell membrane and resistant to degradation and remain metabolically trapped inside the cells. The incorporation of FLT into DNA is less than $1 \%$ [3-5]. Physiological uptake of the tracer is seen in the liver, bone marrow, and urinary tract, as it is renally excreted, while unlike ${ }^{18} \mathrm{~F}$-FDG, it shows no uptake in the brain, skeletal muscles, or myocardium. Variable uptake has been seen in normal gut $[6,7]$.
${ }^{18}$ F-FLT has been synthesized by radiofluorination of various precursors mainly using, as phase-transfer agents during nucleophilic substitution, Kryptofix 222, which provides reliable results and better yields but is difficult to eliminate and disruptive in the purification phase, and tetrabutylammonium hydrogen carbonate (TBA), which shows slightly inferior yields in terms of ${ }^{18} \mathrm{~F}$-Fluoride incorporation but is effectively retained by the strong cationic exchange resin during the purification step $[8,9]$. The production of this radiopharmaceutical was first reported by Wilson et al. [10]. Machulla et al. [11] reported a simplified method for its synthesis, using $5^{\prime}-O$-(4,4'-dimethoxytriphenylmethyl)-2,3'anhydrothymidine, and contemporaneously Grierson and Shields proposed a considerably improved method using 1-(2deoxy-3- $O$-nosyl-5- $O$-DMT- $\beta$-D-threo-pentofuranosyl)-3DMBn-thymine precursors [12]. Subsequently, further improved methods were proposed in the literature, often starting from new precursors; 3- $N$-boc-5'-O-DMTr-3'-Onosyl-lyxothymidine seemed to be the precursor affording the highest incorporation yields of $\left[{ }^{18} \mathrm{~F}\right]$-fluoride and therefore the most widely used [9]. Traditional synthesis of ${ }^{18} \mathrm{~F}$-FLT was associated with low labeling yields (5-20\%) and required difficult and time-consuming high-performance liquid chromatography (HPLC) purification to remove impurity products arising from the leaving group used in the precursor radiofluorination step or the blocking group in the hydrolysis step. Automated synthesis allowed production of ${ }^{18}$ F-FLT in standardized and repeatable conditions, useful for obtaining clinical-grade ${ }^{18}$ F-FLT [1317]. Recently, some new methods allowing synthesis without HPLC purifications and using commercial synthesis modules have been proposed; these procedures reduce the synthesis time and in some cases improve the yield $[9,16,17]$. Many pre-clinical and early preliminary clinical studies were performed as a proof of concept mainly aimed at confirming the feasibility of this new imaging technique [3, 18-20].

The aim of this review is to provide, through a comprehensive analysis of published data, an overall evaluation and description of the diagnostic role of ${ }^{18} \mathrm{~F}$-FLT PET or $\mathrm{PET} / \mathrm{CT}$ in oncology imaging and clinical practice.

\section{Methods}

\section{Search strategy}

A comprehensive computer literature search of the Pub$\mathrm{Med} / \mathrm{Medline}$ databases was conducted to identify relevant published articles on the role of whole-body ${ }^{18}$ F-FLT PET or PET/CT in oncology imaging and clinical practice. We used a search algorithm that was based on a combination of the terms: (a) “ ${ }^{18}$ F-fluorothymidine” OR “ $3{ }^{\prime}$-deoxy-3'-18fluorothymidine" OR "FLT" AND (b) "positron emission 
tomography and positron emission tomography/computed tomography" OR "PET" OR "PET/CT". No beginning date limit was used; the search was updated until August 2012. Only articles in English were selected.

Study selection and data abstraction

Studies investigating the diagnostic role of whole-body ${ }^{18}$ F-FLT PET or PET/CT in clinical oncology were eligible for inclusion. Review articles, editorials, letters, case reports, conference proceedings, radiopharmaceutical kinetic, biodistribution and dosimetry analysis studies, and preclinical studies were excluded from this review. Only those studies including whole-body ${ }^{18}$ F-FLT PET or PET/ CT scans performed in the diagnostic oncology setting were included. The titles and abstracts of the articles were reviewed applying the above-mentioned inclusion and exclusion criteria and rejected in the event of ineligibility. For each included study, information was collected concerning the basic study (author names, journal, year of publication, country of origin), the device used (PET or PET/CT), the tumor studied, and purpose of the imaging evaluation (diagnosis, staging, restaging, therapy response evaluation), the number of patients enrolled, and the main goals of the study. The main findings of the articles included in this review are reported in the results.

\section{Results}

Literature search

The comprehensive computer literature search of the PubMed/Medline databases revealed 371 articles. After reviewing the titles and abstracts, 217 articles were excluded because the reported data were not within the field of interest of this review, because they were preclinical studies, or because they were not in English; 58 articles were excluded because they were editorials or reviews; 10 articles were excluded because they were case reports (Fig. 1). Finally, 86 articles were selected $[6,7,21-$ 104] and retrieved in full-text version.

\section{Literature data: report and discussion}

The overall assessment of the published studies clearly shows heterogeneity both of the tumors analyzed and of the reasons for performing the evaluations (diagnosis, staging, restaging, and therapy response evaluation). All the retrieved papers were published in the period between 2003 and 2012. The tumor or organ most frequently analyzed was the lung (Table 1), in 19 studies [21-39]; the digestive tract (including the esophagus, stomach, colorectal tract, pancreas and liver; Table 2) was analyzed in 17 papers [40-56], brain tumors (Table 3) in 15 [57-71], head and neck tumors (Table 4) in nine [72-80], myeloproliferative/ lymphoproliferative diseases (Table 5) in nine $[6,7,81-$ 87], breast cancer (Table 6) in six [88-93], and all the others (including melanomas, sarcomas, ovarian cancer, uterine cancer, germ cell tumors, neuroendocrine tumors; Table 7) in 11 [94-104]. Twenty-four studies were performed in Germany, 15 in the United States, 14 in Japan, 13 in the Netherlands, six in China, five in the United Kingdom, four in South Korea, two in France, two in Austria, and one in India (Tables 1, 2, 3, 4, 5, 6, 7). The number of patients enrolled in the studies was very low, ranging from five to 73 ; despite the low number of patients enrolled, almost all the studies were prospective (only two were retrospective). The injected activity ranged from 104 to $555 \mathrm{MBq}$, reaching an average of between 200 and $400 \mathrm{MBq}$; the waiting time after injection before imaging acquisition ranged from 30 to $120 \mathrm{~min}$, but was most frequently in the range of 45-60 min.

\section{Lung}

Even though ${ }^{18}$ F-FDG PET shows high sensitivity and good specificity in evaluating lung cancer and lung nodules and differentiating malignant from benign lesions, falsepositive results, mainly due to inflammation are still a problem. Consequently, a more specific tracer would be desirable and ${ }^{18} \mathrm{~F}$-FLT, which shows lower uptake in inflammatory tissues, has been proposed. Nineteen studies analyzed the role of ${ }^{18} \mathrm{~F}$-FLT PET or PET/CT in lung nodules or cancer, performed for different purposes: diagnosis, staging, restaging, and therapy response evaluation (Table 1). Although many studies suggest a possible role for ${ }^{18} \mathrm{~F}$-FLT imaging in this field, on the basis of the biological added value of the technique, many others show its diagnostic performance to be lower than that of ${ }^{18} \mathrm{~F}-\mathrm{FDG}$ [21-25, 28, 29, 31, 33, 38]. Buck et al. [21] evaluated 26 patients with pulmonary nodules with ${ }^{18} \mathrm{~F}$-FDG PET and ${ }^{18}$ F-FLT PET. ${ }^{18}$ F-FDG PET was false-negative in a carcinoma in situ, in a non-small-cell-lung-cancer (NSCLC) with a low proliferation index, and in a patient with lung metastases from colorectal cancer; on the other hand, increased uptake was related exclusively to malignant tumors. Cobben et al. [22] investigated 16 patients with stage IB-IV NSCLC and one patient in whom NSCLC was strongly suspected. Staging by ${ }^{18}$ F-FLT PET was correct in eight of the 17 patients; the maximal and mean standardized uptake value (SUV) of ${ }^{18}$ F-FLT PET was significantly lower than that of ${ }^{18}$ F-FDG PET. ${ }^{18}$ F-FLT PET was not judged useful for staging and restaging. Buck et al. [23] investigated 47 patients with pulmonary nodules on chest CT with ${ }^{18}$ F-FLT PET; 43 also underwent ${ }^{18}$ F-FDG PET. 
Fig. 1 Flow-chart of the search strategy and graph showing the number of articles per tumor type

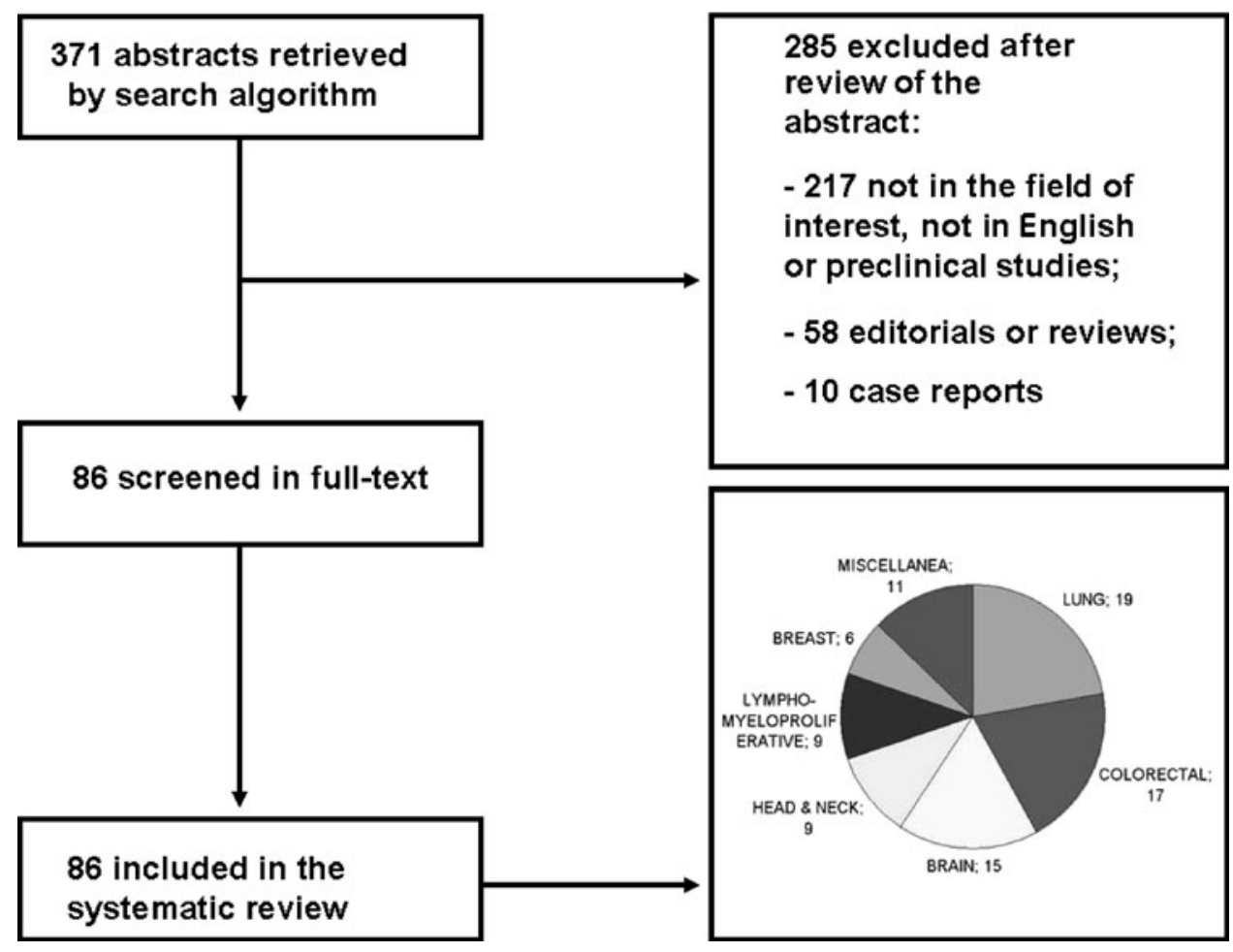

The sensitivity of ${ }^{18}$ F-FLT PET for detection of lung cancer was $90 \%$, the specificity $100 \%$, and the accuracy (AC) $94 \%$, but in patients with mediastinal lymph-node metastases, the sensitivity was $53 \%$. Clinical TNM stage was correctly identified in $67 \%$ patients, compared to $85 \%$ with ${ }^{18}$ F-FDG PET, showing that ${ }^{18}$ F-FLT PET had a high specificity for the detection of malignant tumors, but was less accurate than ${ }^{18} \mathrm{~F}-\mathrm{FDG}$ for $\mathrm{N}$-staging and for detection of lung metastases. In a study by Yap et al. [24], 11 patients with lung nodules and 11 with NSCLC underwent ${ }^{18}$ F-FLT PET and ${ }^{18}$ F-FDG PET, with results compared to pathology findings; because of the finding of a low sensitivity, ${ }^{18}$ F-FLT PET did not appear to be suitable to replace ${ }^{18}$ F-FDG PET for tumor staging or for characterization of nodules. In a study by Yamamoto et al. [25], 18 patients with NSCLC underwent ${ }^{18}$ F-FLT PET and ${ }^{18}$ F-FDG PET, which showed a sensitivity for the detection of lung cancer of 72 and $89 \%$, respectively. In another study by Yamamoto et al. [28], 54 patients with newly diagnosed pulmonary nodules suggestive of a malignant tumor were studied with both ${ }^{18}$ F-FLT and ${ }^{18}$ F-FDG. The specificity of ${ }^{18}$ F-FLT was significantly higher than that of ${ }^{18} \mathrm{~F}-\mathrm{FDG}$, but the uptake in lung cancer was significantly lower. The same group [29] analyzed 34 patients with NSCLC who underwent ${ }^{18}$ F-FLT PET and ${ }^{18}$ F-FDG PET. For the depiction of primary tumor, ${ }^{18}$ F-FLT PET showed a sensitivity of $67 \%$, compared with $94 \%$ for ${ }^{18} \mathrm{~F}-\mathrm{FDG}$ PET. Yang et al. [31] evaluated 31 patients with NSCLC with ${ }^{18}$ F-FLT PET/CT and ${ }^{18}$ F-FDG PET/CT before surgery. ${ }^{18}$ F-FLT PET/CT resulted in more downstaged but fewer upstaged patients than ${ }^{18}$ F-FDG PET/CT (considering N-staging). Mileshkin et al. [33] evaluated 74 patients with locally advanced or metastatic, recurrent, or refractory NSCLC, submitted to ${ }^{18}$ F-FDG PET and ${ }^{18}$ F-FLT PET; they found the results of ${ }^{18} \mathrm{~F}-\mathrm{FDG}$ to be more informative because ${ }^{18}$ F-FLT showed a lower uptake than ${ }^{18}$ F-FDG in many lesions and a relatively high background uptake (particularly in liver and bone marrow). Moreover, two studies showed the added value of dual-tracer imaging. In a study by Tian et al. [27], 55 patients with lung nodules (16 with malignant tumor, 16 with tuberculosis, and 23 with other benign lesions) underwent both ${ }^{18}$ F-FLT PET/CT and ${ }^{18} \mathrm{~F}$-FDG PET/CT; the sensitivity and specificity of ${ }^{18} \mathrm{~F}$ FDG and ${ }^{18}$ F-FLT were 87.5 and $58.97 \%$ and 68.75 and $76.92 \%$, respectively. Combining the two tracers increased the sensitivity and specificity to 100 and $89.74 \%$. The study showed that the dual-tracer PET/CT, by reflecting different biological features, improved the diagnostic AC. Xu et al. [36] evaluated 73 subjects with lung nodules with ${ }^{18} \mathrm{~F}$-FDG and ${ }^{18} \mathrm{~F}$-FLT. ${ }^{18} \mathrm{~F}$-FDG PET had a sensitivity for lung tumor of $89.3 \%$, while the specificity was $26.7 \% .{ }^{18}$ F-FLT PET alone had almost the same sensitivity as ${ }^{18} \mathrm{~F}-\mathrm{FDG}(85.7 \%)$ for malignant tumors, and a slightly better specificity (40\%). When the two imaging modalities were combined, the diagnostic performance improved. ${ }^{18} \mathrm{~F}-\mathrm{FLT} /{ }^{18} \mathrm{~F}-\mathrm{FDG}$ PET/CT was shown to be of clinical value in improving the diagnostic confidence in 28 lung tumors, 18 tuberculoses, and 27 other 


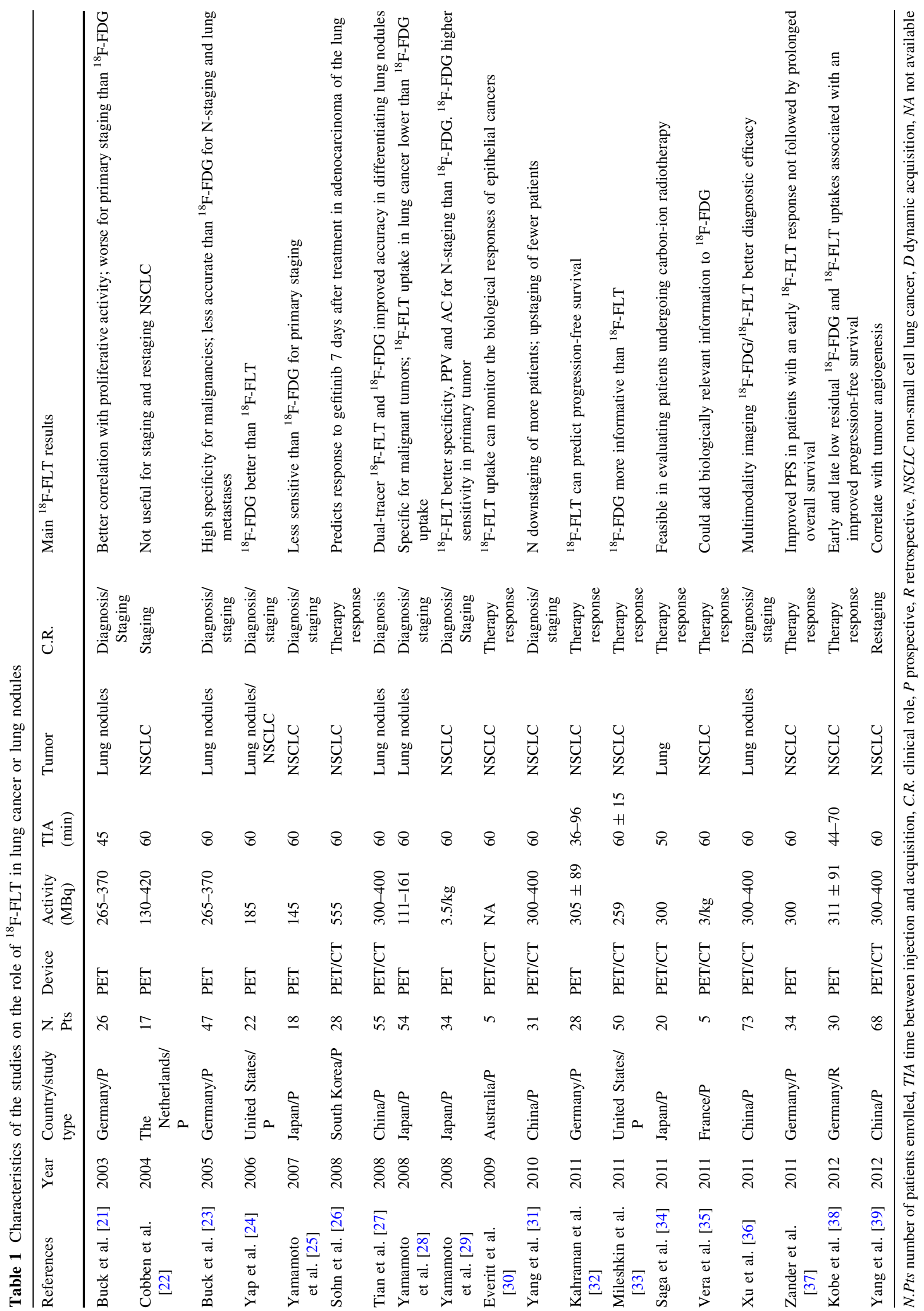




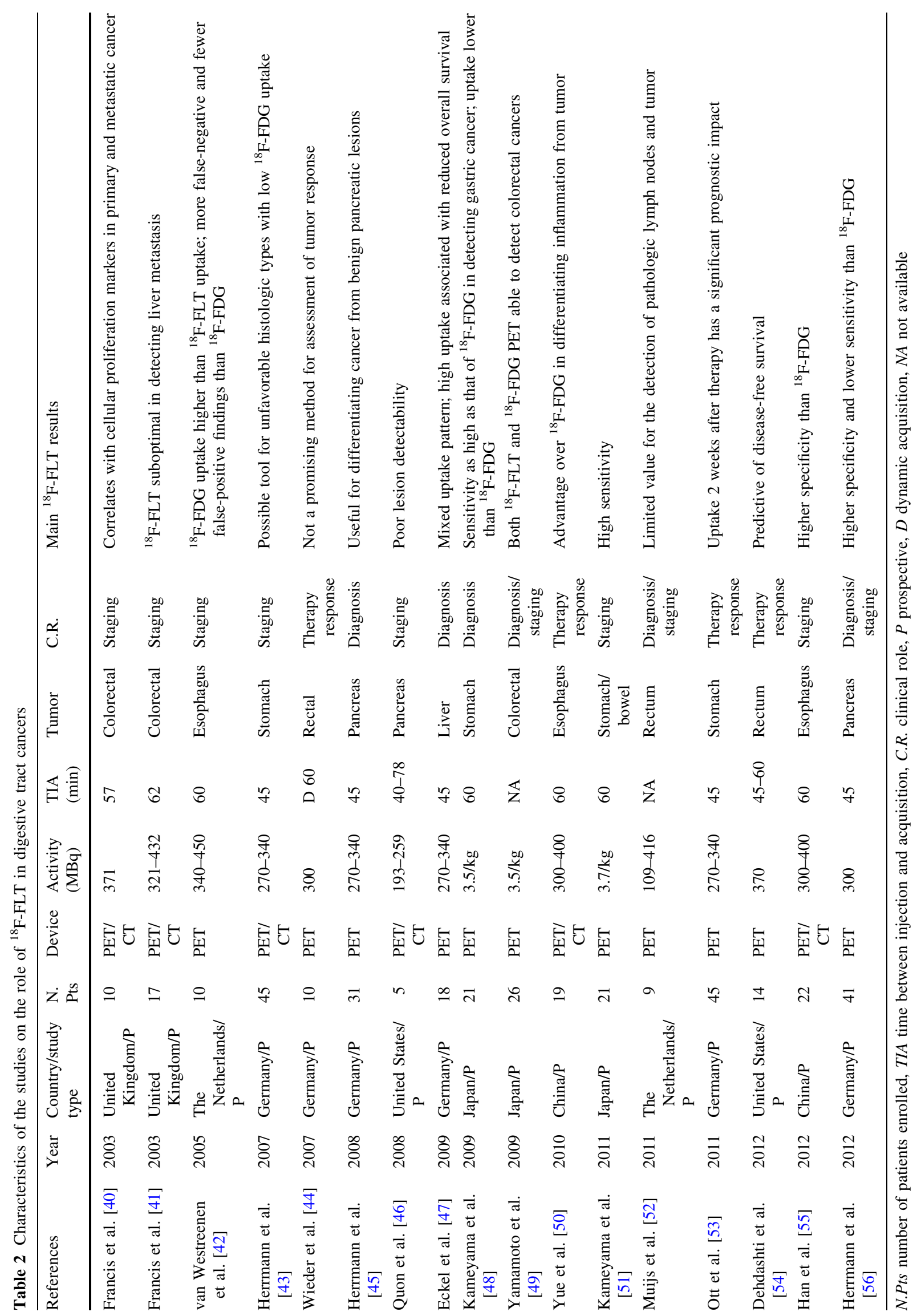




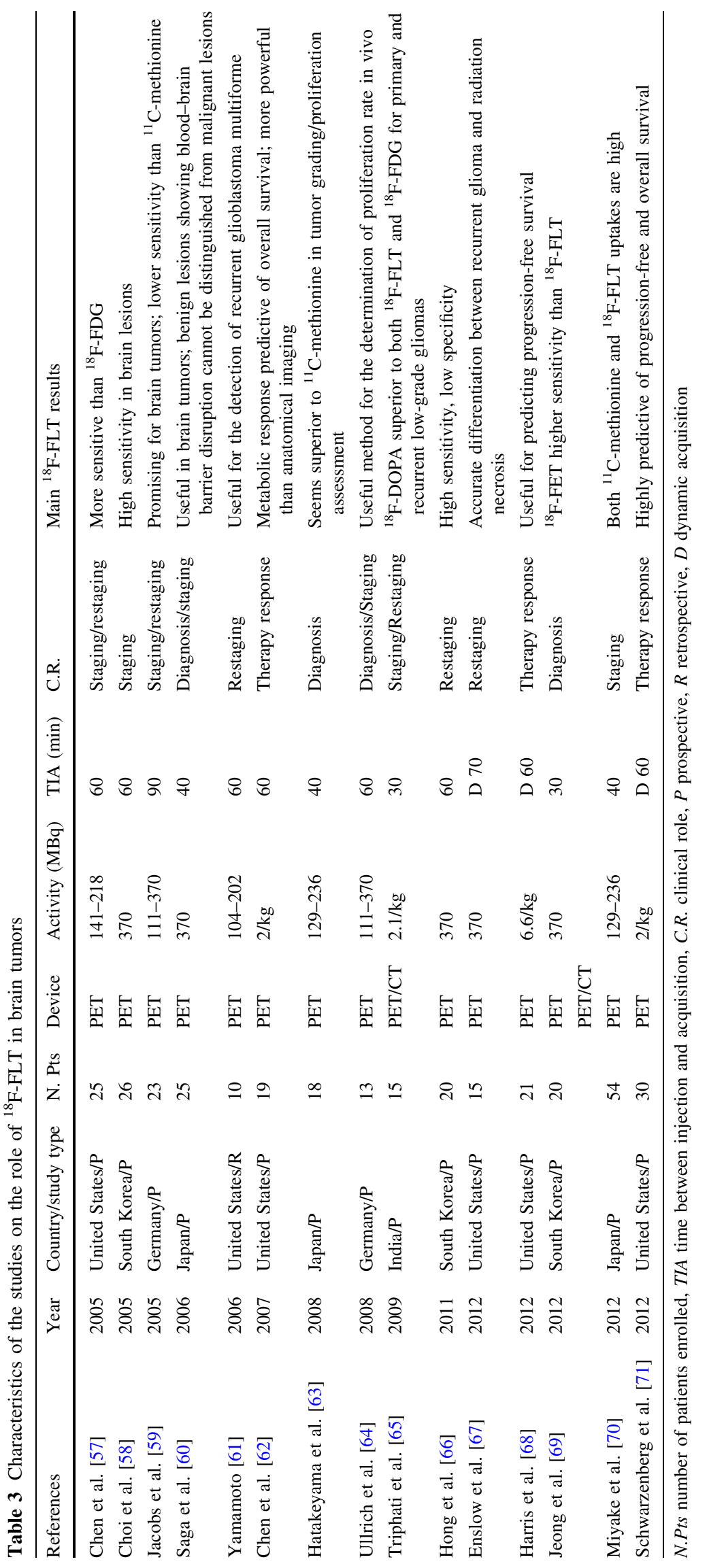




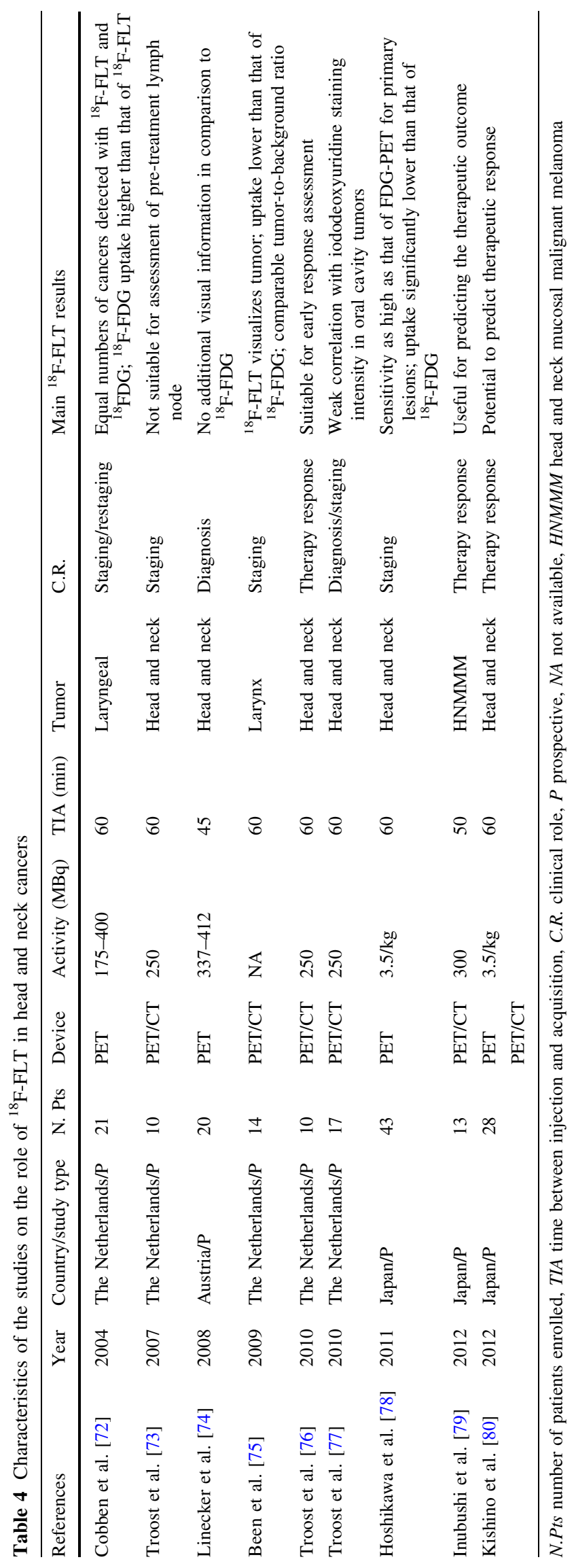




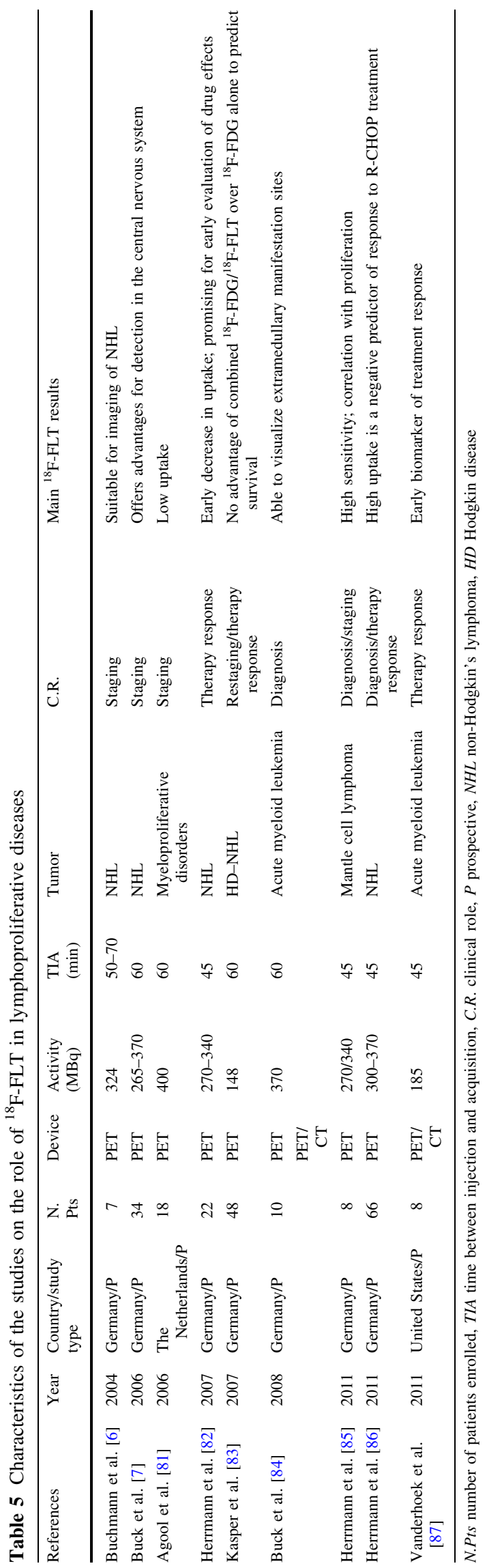

benign lesions. Multimodality imaging prompted a substantial change in clinical management in $31.5 \%$ of the study subjects and a partial change in another $12.3 \%$. The most promising results concerned therapy response evaluation as the technique seemed to be useful in monitoring biological response, predicting early response, and predicting progression-free survival $[26,30,32,34,35,37$, 39]. Sohn et al. [26] evaluated 28 patients with advanced or recurrent adenocarcinoma of the lung with ${ }^{18} \mathrm{~F}$-FLT PET/ $\mathrm{CT}$ to assess early changes in uptake after gefitinib therapy; at 7 days after initiation, the percent changes in $S_{U V} V_{\max }$ were significantly different, and a decrease of $>10.9 \%$ in $\mathrm{SUV}_{\text {max }}$ was used as the criterion for predicting response. The positive and negative predictive values (PPV, NPV) were both $92.9 \%$, and ${ }^{18}$ F-FLT PET/CT was judged useful in predicting therapy response. In the study by Everitt et al. [30], in which five patients with locally advanced NSCLC underwent serial ${ }^{18}$ F-FLT PET/CT scans during chemoradiotherapy (CMRT), it was found that ${ }^{18} \mathrm{~F}-\mathrm{FLT}$ uptake can monitor the distinctive biological responses of epithelial cancers and highly radiosensitive normal tissue changes. Kobe et al. [38], Kahraman et al. [32], and Zander et al. [37] analyzed, from different perspectives, a group of patients with untreated stage-IV NSCLC who, enrolled in a phase-II clinical trial, had undergone a combined ${ }^{18} \mathrm{~F}-\mathrm{FDG}$ PET and ${ }^{18}$ F-FLT PET scan at 1 week and 6 weeks after erlotinib treatment. Kobe et al. [38] documented that early and late low residual ${ }^{18}$ F-FDG and ${ }^{18}$ F-FLT uptakes were associated with improved progression-free survival; residual ${ }^{18} \mathrm{~F}$-FLT uptake did not prove helpful for prediction of short-term outcome. Kahraman et al. [32] showed that early ${ }^{18} \mathrm{~F}$-FDG PET and ${ }^{18}$ F-FLT PET can predict progression-free survival, but ${ }^{18} \mathrm{~F}-\mathrm{FDG}$ might be the most robust to use for early response prediction. Moreover, they showed that metabolically active volume measurement in early ${ }^{18}$ F-FLT PET and late ${ }^{18}$ F-FDG PET may have additional predictive value in monitoring response. Zander et al. [37] showed improved progression-free survival in patients with an early ${ }^{18} \mathrm{~F}$-FDG response followed by prolonged overall survival, but not in patients with an early ${ }^{18}$ F-FLT response. In the study by Saga et al. [34], 20 consecutive patients with lung cancer underwent ${ }^{18} \mathrm{~F}$-FLT PET/CT before and after carbon-ion radiotherapy (CIRT). Primary responses to CIRT were partial in 13 patients, stable disease in six patients, and non-evaluable in one patient. Kaplan-Meier analysis supported the prognostic value of pre-CIRT ${ }^{18}$ F-FLT PET/CT. Vera et al. [35] studied five patients with NSCLC (candidates for curativeintent RT) with ${ }^{18} \mathrm{~F}$-FLT, ${ }^{18} \mathrm{~F}$-misonidasole $\left({ }^{18} \mathrm{~F}\right.$-FMISO) and ${ }^{18} \mathrm{~F}$-FDG PET/CT; their findings suggested that ${ }^{18}$ F-FLT and ${ }^{18}$ F-FMISO would complement ${ }^{18}$ F-FDG PET/CT before RT. Yang et al. [39] studied 68 patients with proven or suspected NSCLC who underwent ${ }^{18}$ F-FLT 


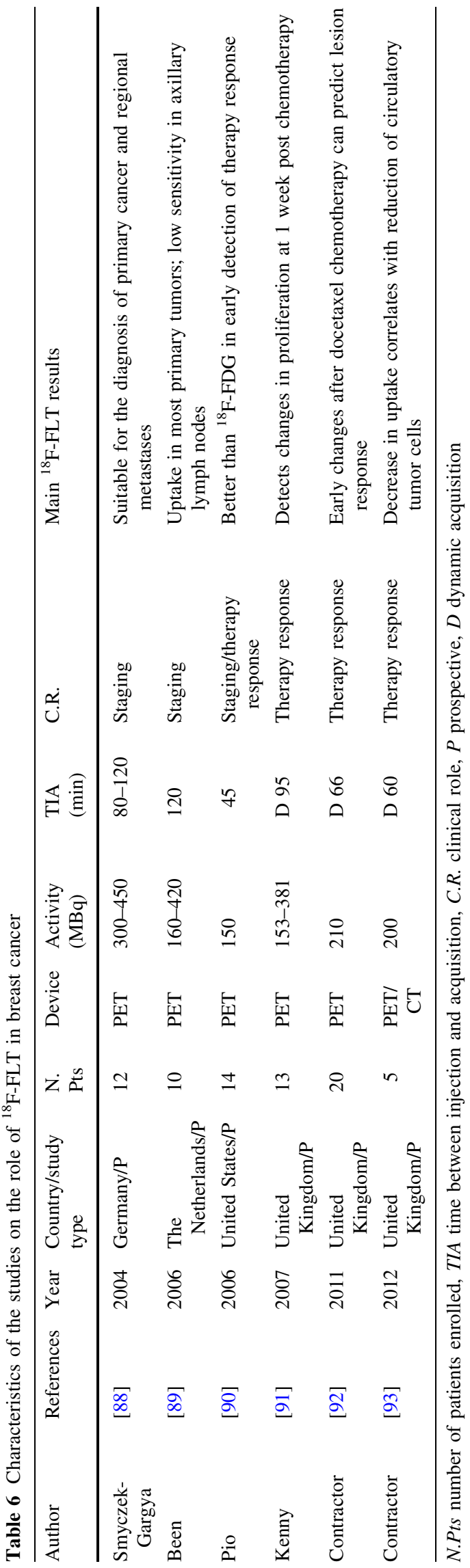

PET/CT before surgery. Imaging correlated with tumor angiogenesis (fundamental in the growth, progression and metastases of solid tumors), as reflected by anti-CD105$\mathrm{mAb}$ intratumoral microvessel density (CD105-MVD) immunohistochemical findings, and the authors suggested that it may be helpful in assessing antiangiogenic therapy.

In the articles analyzed, ${ }^{18}$ F-FLT PET was found to perform worse than ${ }^{18} \mathrm{~F}-\mathrm{FDG}$ when used for staging and restaging, but it seemed promising for therapy response evaluation in concordance with pathology findings.

\section{Digestive tract}

The digestive tract is an interesting diagnostic setting because is composed of many different organs (e.g., liver and colon) with different ${ }^{18}$ F-FDG uptake patterns, which can sometimes affect diagnostic accuracy (especially in diabetic patients treated with oral hypoglycemic drugs).

Seventeen studies analyzed the role of ${ }^{18}$ F-FLT PET or PET/CT in digestive tract cancers (Table 2). The role of ${ }^{18}$ F-FLT in colorectal cancer (CRC) imaging was analyzed in six studies. Francis et al. [40] prospectively studied 13 lesions from 10 patients with primary or recurrent CRC. Histology confirmed adenocarcinoma in 12/13 lesions. All eight extrahepatic lesions were visualized using ${ }^{18} \mathrm{~F}-\mathrm{FLT}$, and $3 / 5$ resected liver metastases were avid for ${ }^{18}$ F-FLT and showed high proliferation, while the remaining two lesions demonstrated no uptake of ${ }^{18} \mathrm{~F}$-FLT and, correspondingly, showed very low proliferation. A statistically significant positive correlation was found between the SUV of the tumors visualized with ${ }^{18} \mathrm{~F}$-FLT and the corresponding MIB-1 labeling indices. ${ }^{18}$ F-FLT PET correlated with cell proliferation markers in both primary and metastatic CRC and provided a mechanism for in vivo grading of malignancy. Moreover, Francis et al. [41] in the same year compared the cellular uptake of ${ }^{18}$ F-FLT and ${ }^{18}$ F-FDG in patients with $\mathrm{CRC}$, analyzing 17 patients with 50 primary or metastatic lesions. All the primary tumors were visualized by both tracers, with ${ }^{18}$ F-FDG showing on average twice the uptake of ${ }^{18}$ F-FLT. Similar uptake of both tracers was seen in lung and peritoneal lesions. Of the 32 colorectal liver metastases, 11 (34\%) were seen to be avid for ${ }^{18}$ F-FLT, compared with 31 (97\%) for ${ }^{18}$ F-FDG. ${ }^{18}$ F-FLT showed a high sensitivity in the detection of extrahepatic disease but a poor sensitivity for the imaging of colorectal liver metastases, limiting its role as a diagnostic tracer in CRC. Yamamoto et al. [49] examined 26 CRC patients with ${ }^{18}$ F-FLT PET and ${ }^{18}$ F-FDG PET. In all the patients, $\mathrm{CRC}$ was detected by both tracers, and there was no significant correlation between the Ki-67 index and either ${ }^{18}$ F-FLT or ${ }^{18}$ F-FDG SUV. In a study by Muijs et al. [52], nine patients with rectal cancer (RC) underwent CT and ${ }^{18}$ F-FLT PET prior to therapy. ${ }^{18}$ F-FLT PET visualized 


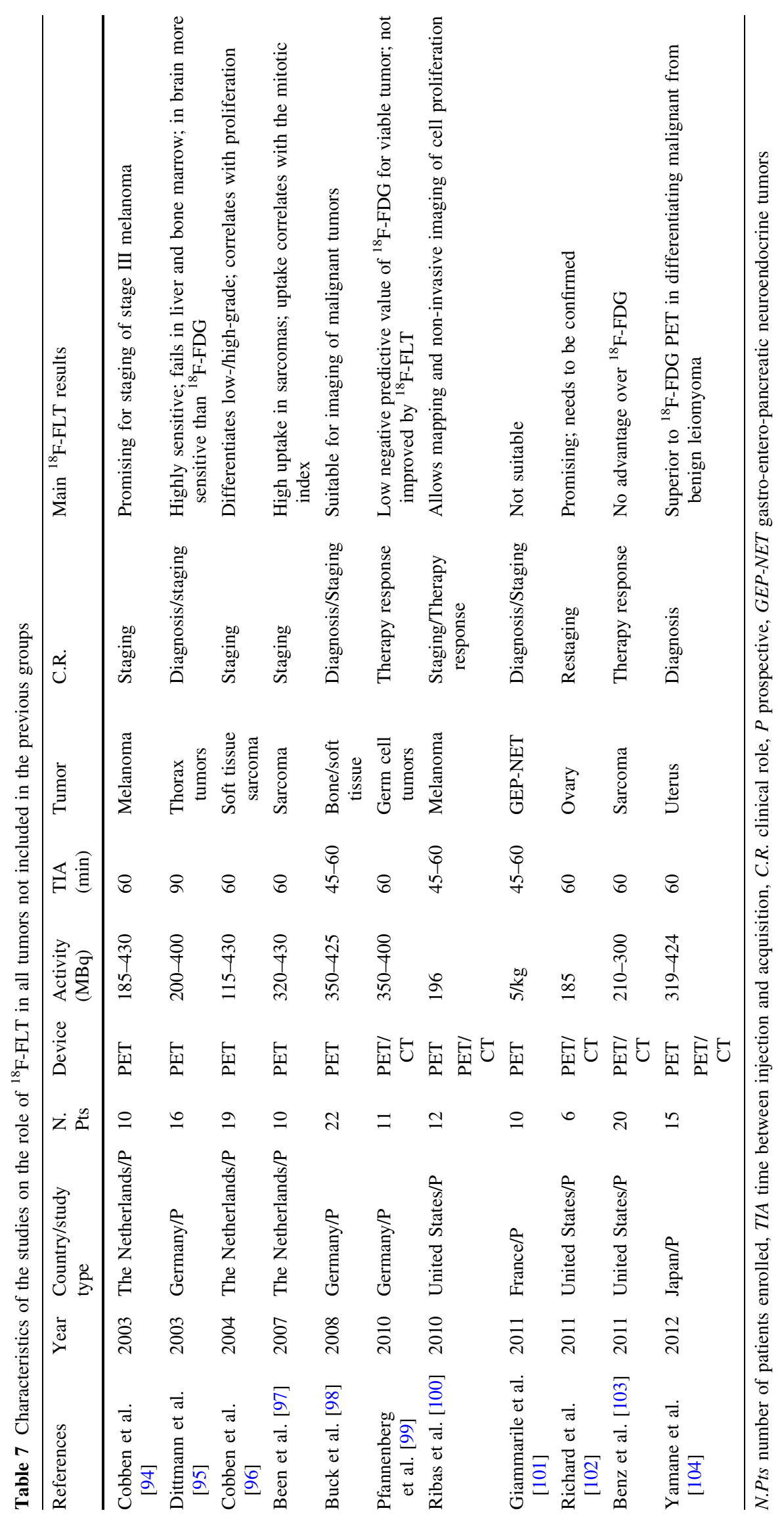


$7 / 9$ cancers ( $78 \%$ ) but was not able to visualize pathologic lymph nodes, thus showing itself to be of limited value for this purpose. In a study by Wieder et al. [44], 10 patients with locally advanced RC underwent ${ }^{18} \mathrm{~F}$-FLT PET prior to therapy, 2 weeks after initiation and 3-4 weeks after CMRT. CMRT caused a significant reduction in tumor uptake, but the degree of change in uptake was not correlated with tumor response showing the technique to be unsuitable for assessment of tumor response. In a study by Dehdashti et al. [54], 14 patients with locally advanced RC underwent ${ }^{18}$ F-FDG PET and ${ }^{18}$ F-FLT PET before therapy and ${ }^{18}$ F-FLT approximately 2 weeks after initiating neoadjuvant CMRT. Pre-therapy ${ }^{18} \mathrm{~F}$-FDG uptake, during-therapy ${ }^{18} \mathrm{~F}$-FLT uptake, and percentage change in ${ }^{18} \mathrm{~F}$-FLT uptake were found to be equally predictive of disease-free survival.

The role of ${ }^{18} \mathrm{~F}$-FLT in gastric cancer (GC) imaging has been analyzed in four articles. In the study by Kameyama et al. [51], 21 patients with newly diagnosed gastrointestinal cancers (11 CRC, $10 \mathrm{GC}$ ) were examined with ${ }^{18} \mathrm{~F}$ FLT PET. Focally increased uptake was visible in 20/21 patients with cancer lesions with a sensitivity of $95.2 \%$. Herrmann et al. [43] evaluated 45 consecutive patients with a diagnosis of locally advanced GC with both ${ }^{18}$ F-FLT PET and ${ }^{18} \mathrm{~F}$-FDG PET; they showed that ${ }^{18} \mathrm{~F}$-FLT is a feasible tool for imaging tumors of an unfavorable histologic type with low ${ }^{18}$ F-FDG uptake. The same group of patients was analyzed with ${ }^{18}$ F-FDG and ${ }^{18}$ F-FLT before and 2 weeks after initiation of chemotherapy in the study by Ott et al. [53]. ${ }^{18}$ F-FLT uptake two weeks after initiation of therapy was shown to be the only imaging parameter with significant prognostic impact. In the study by Kameyama et al. [48], 21 patients with newly diagnosed advanced GC were examined with ${ }^{18}$ F-FLT PET and ${ }^{18}$ F-FDG PET. The sensitivity of ${ }^{18}$ F-FLT PET and ${ }^{18}$ F-FDG PET for detection of advanced GC was 95.2 and $95.0 \%$, respectively. The sensitivity of ${ }^{18} \mathrm{~F}$-FLT PET was seen to be as high as that of ${ }^{18} \mathrm{~F}$-FDG PET for the detection of GC, although uptake was significantly lower.

The role of ${ }^{18}$ F-FLT in esophageal cancer (EC) imaging has been analyzed in three articles. In the study by van Westreenen et al. [42], 10 patients with cancer of the esophagus or gastroesophageal junction were staged with $\mathrm{CT}$, endoscopic ultrasonography, and ultrasound of the neck. In addition, all patients underwent a whole-body ${ }^{18} \mathrm{~F}$ FLT PET and ${ }^{18}$ F-FDG PET. ${ }^{18}$ F-FDG PET was able to detect all EC, whereas ${ }^{18}$ F-FLT-PET visualized the tumor in $8 / 10$ patients. Both detected lymph-node metastases in $2 / 8$ patients. ${ }^{18}$ F-FDG PET detected one cervical lymph node that was missed on ${ }^{18} \mathrm{~F}$-FLT PET, whereas ${ }^{18} \mathrm{~F}$-FDG PET showed uptake in benign lesions in two patients. Uptake of ${ }^{18} \mathrm{~F}$-FDG in EC was significantly higher than that of ${ }^{18} \mathrm{~F}$-FLT, and the ${ }^{18} \mathrm{~F}$-FLT scans showed more falsenegative findings and fewer false-positive findings than the
${ }^{18}$ F-FDG ones. Han et al. [55] used ${ }^{18}$ F-FDG PET/CT and ${ }^{18}$ F-FLT PET/CT to study 22 patients affected by untreated thoracic esophageal squamous cell carcinoma (ESCC) in order to assess their $\mathrm{AC}$ in detecting metastatic lymph nodes. The sensitivity, specificity, AC, PPV, and NPV of ${ }^{18} \mathrm{~F}$-FLT PET/CT were 74.47, 99.20, 96.46, 92.11, and $96.89 \%$, respectively, whereas those of ${ }^{18} \mathrm{~F}$-FDG PET/CT were $82.98,96.29,94.81,82.98$, and $96.29 \%$, respectively. ${ }^{18} \mathrm{~F}$-FLT uptake in regional lymph nodes in ESCC was significantly lower than ${ }^{18} \mathrm{~F}$-FDG uptake and showed fewer false-positive findings and a higher specificity. Yue et al. [50] evaluated 19 patients with inoperable ESCC who underwent serial ${ }^{18}$ F-FLT PET/CT during RT. Patients who underwent scans after completing the entire RT course showed no tumor uptake on ${ }^{18}$ F-FLT PET/CT but high uptake on ${ }^{18} \mathrm{~F}$-FDG PET/CT. Pathologic examination of these regions revealed inflammatory infiltrates but no residual tumor. ${ }^{18}$ F-FLT uptake was used to monitor the biologic response of ESCC and normal tissue to RT and showed an advantage over ${ }^{18} \mathrm{~F}-\mathrm{FDG}$ in differentiating inflammation from tumor.

The role of ${ }^{18} \mathrm{~F}$-FLT in pancreatic cancer imaging has been analyzed in three articles. In the study by Herrmann et al. [45], ${ }^{18}$ F-FLT PET was performed in 31 patients with undefined pancreatic lesions; all 10 benign pancreatic lesions were negative on ${ }^{18} \mathrm{~F}$-FLT, and $15 / 21$ malignant tumors presented focal ${ }^{18} \mathrm{~F}$-FLT uptake that was higher than the surrounding background uptake (sensitivity $71.4 \%) .{ }^{18}$ F-FLT PET missed four well-differentiated and 2-T1 cancers. In the study by Quon et al. [46], five patients with newly diagnosed and previously untreated pancreatic adenocarcinoma underwent ${ }^{18} \mathrm{~F}$-FLT PET/CT, ${ }^{18} \mathrm{~F}$-FDG PET/CT and contrast-enhanced CT before treatment. ${ }^{18} \mathrm{~F}$ FLT PET/CT showed poor lesion detectability and relatively low levels of radiotracer uptake in the primary tumor. Herrmann et al. [56] evaluated 41 patients affected by pancreatic lesions with ${ }^{18} \mathrm{~F}$-FLT PET and ${ }^{18} \mathrm{~F}$-FDG PET/CT. Of the 41 patients, 33 had a malignancy and eight patients had benign disease. Visual analysis of ${ }^{18} \mathrm{~F}-\mathrm{FDG}$ and ${ }^{18} \mathrm{~F}$-FLT resulted in sensitivity values of 91 and $70 \%$, respectively, and specificity values of 50 and $75 \%$, respectively. For differentiation of pancreatic tumors, ${ }^{18} \mathrm{~F}$ FDG PET/CT showed a higher sensitivity but lower specificity than ${ }^{18}$ F-FLT PET.

The role of ${ }^{18} \mathrm{~F}$-FLT in hepatic cancer imaging has been analyzed only by Eckel et al. [47]; ${ }^{18}$ F-FLT PET was performed in 18 untreated patients with liver lesions suspected to be hepatocellular carcinoma (HCC). HCC tumors showed a mixed uptake pattern for the in vivo proliferation marker ${ }^{18}$ F-FLT. A total of $69 \%$ of the HCC lesions showed ${ }^{18}$ F-FLT uptake which was higher than that of the surrounding liver tissue, whereas the remaining lesions were photopenic or contained a mixture of hot and cold 
lesions. High initial ${ }^{18}$ F-FLT uptake was associated with reduced overall survival.

In the articles analyzed, ${ }^{18}$ F-FLT showed a lower falsepositive rate than ${ }^{18} \mathrm{~F}-\mathrm{FDG}$ and a potential usefulness, described in some papers, in histological types with low ${ }^{18}$ F-FDG uptake. Despite this, ${ }^{18}$ F-FLT PET did not record significantly better diagnostic performances than ${ }^{18} \mathrm{~F}-\mathrm{FDG}$; in particular, it showed a poor ability to detect hepatic metastases.

\section{Brain}

As a consequence of its low background uptake in normal brain tissue, probably due to its low proliferation rate, ${ }^{18} \mathrm{~F}$ FLT has been proposed as an alternative to ${ }^{18} \mathrm{~F}-\mathrm{FDG}$, which is instead characterized by high uptake, for the evaluation of brain tumors. The role of ${ }^{18} \mathrm{~F}$-FLT in brain tumor imaging was analyzed in 15 articles. Chen et al. [57] evaluated 25 patients with newly diagnosed or previously treated gliomas with both ${ }^{18} \mathrm{~F}$-FLT and ${ }^{18} \mathrm{~F}$-FDG. Three stable patients in long-term remission were included as negative control subjects and more than half of the patients underwent resection after the PET study to correlate uptake and the Ki-67 proliferation index. ${ }^{18} \mathrm{~F}$-FLT visualized all 18 high-grade tumors; low-grade tumors that did not show contrast enhancement on magnetic resonance (MR) with gadopentetate dimeglumine (Gd-DTPA) were not visualized; neither were all three stable lesions in patients in long-term remission; ${ }^{18}$ F-FLT was $100 \%$ sensitive and specific in all high-grade gliomas. Five patients with previously treated high-grade gliomas were considered stable on the basis of MR and clinical criteria before the PET study. ${ }^{18}$ F-FLT PET studies were positive, while ${ }^{18}$ F-FDG studies were negative, but all patients had tumor progression; ${ }^{18} \mathrm{~F}$-FLT appeared more accurate (sensitivity $100 \%$; specificity $100 \%$ ) in identifying recurrent high-grade glioma than ${ }^{18} \mathrm{~F}$-FDG (sensitivity $72 \%$; specificity $100 \%$ ). ${ }^{18}$ F-FLT uptake correlated significantly better with the Ki-67 proliferation index than did ${ }^{18} \mathrm{~F}$-FDG; ${ }^{18} \mathrm{~F}$-FLT PET also had better prognostic power than ${ }^{18} \mathrm{~F}$-FDG to predict the time to tumor progression, as well as survival. In the study by Choi et al. [58], 26 patients with brain tumors $(n=18)$ or non-tumorous lesions $(n=8)$ underwent ${ }^{18} \mathrm{~F}$ FDG PET and ${ }^{18}$ F-FLT PET imaging. Among the 18 brain tumors, ${ }^{18} \mathrm{~F}$-FLT showed increased uptake in all 12 highgrade tumors but ${ }^{18} \mathrm{~F}$-FDG uptake was variable. In 22 brain lesions with similar or decreased uptake compared with normal gray matter on ${ }^{18} \mathrm{~F}-\mathrm{FDG}$, the sensitivity and specificity of ${ }^{18}$ F-FLT were 79 and $63 \%$, respectively. The uptake ratios of brain tumors on ${ }^{18} \mathrm{~F}$-FLT were significantly higher than the lesion-to-gray matter ratios and lesion-towhite matter ratios of ${ }^{18}$ F-FDG uptake and differed significantly between high- and low-grade tumors. Moreover,
${ }^{18}$ F-FLT uptake was significantly correlated with the Ki-67 proliferation index. These findings indicated that ${ }^{18} \mathrm{~F}$-FLT PET was useful for evaluating tumor grade and cell proliferation. It displayed a high sensitivity and good contrast in evaluating brain lesions that showed similar or decreased uptake compared with normal gray matter on ${ }^{18} \mathrm{~F}$-FDG. In the study by Tripathi et al. [65], 15 patients ( 2 patients in remission as controls) with newly diagnosed or previously treated low-grade gliomas underwent ${ }^{18} \mathrm{~F}$-DOPA,${ }^{18} \mathrm{~F}$-FDG, and ${ }^{18} \mathrm{~F}$-FLT PET/CT studies on consecutive days. ${ }^{18} \mathrm{~F}$ DOPA was positive in all primary and recurrent low-grade glioma cases and negative in the patients in remission. Tumor was visualized on ${ }^{18} \mathrm{~F}$-FDG in seven of the 13 cases, and on ${ }^{18} \mathrm{~F}$-FLT in four of the 13 cases. ${ }^{18} \mathrm{~F}$-DOPA scan was superior to both ${ }^{18} \mathrm{~F}$-FLT and ${ }^{18} \mathrm{~F}$-FDG for visualization of primary and recurrent low-grade gliomas. ${ }^{18} \mathrm{~F}$-FLT was not recommended for evaluation of recurrent lowgrade gliomas. Twenty patients with suspected recurrence on brain MR after surgical removal of the primary tumor were included in the study of Hong et al. [66]. Of 20 lesions, 15 were recurrences and ${ }^{18}$ F-FLT PET showed a high diagnostic sensitivity (15/15) and a moderate specificity $(3 / 5) .{ }^{18}$ F-FDG PET showed moderate diagnostic sensitivity (11/15) and specificity (4/5). All the four recurrent tumors without ${ }^{18} \mathrm{~F}$-FDG uptake showed ${ }^{18} \mathrm{~F}$-FLT uptake. The authors demonstrated that ${ }^{18}$ F-FLT PET had a higher sensitivity to detect a recurrent brain tumor due to the high contrast of tumor to normal tissue, but, due to the lower specificity, a limited value as a complementary tool to MR for differentiating recurrence from radiationinduced change; the possible explanation was that ${ }^{18} \mathrm{~F}$-FLT cannot be transported across intact blood-brain barrier (BBB), but can cross the disrupted BBB of not only neoplastic lesions but also inflammation or necrosis. In the study by Enslow et al. [67], 15 patients with suspected recurrence of treated grade 2 glioma were studied with ${ }^{18} \mathrm{~F}$ FDG and ${ }^{18}$ F-FLT PET. Both quantitative and visual determinations allowed accurate differentiation between recurrent glioma and radiation necrosis with both tracers. In the study by Jacobs et al. [59], PET scanning was performed with ${ }^{18} \mathrm{~F}$-FLT and L-(S-methyl- $\left.\left[{ }^{11} \mathrm{C}\right]\right)$ methionine, $\left(\left[{ }^{11} \mathrm{C}\right]\right.$ methionine $)$ were performed on 23 patients with histologically verified gliomas of different grades. Uptake ratios of ${ }^{18} \mathrm{~F}$-FLT were higher than uptake ratios of ${ }^{11} \mathrm{C}$-methionine, but the sensitivity for the detection of tumors was lower for ${ }^{18} \mathrm{~F}$-FLT than for ${ }^{11} \mathrm{C}$-methionine (78.3 vs $91.3 \%$ ), especially for low-grade astrocytomas. Uptake ratios of ${ }^{18} \mathrm{~F}$-FLT were higher in glioblastomas than in astrocytomas. In the study by Hatakeyama et al. [63], among 41 patients with newly diagnosed gliomas, 18 underwent both ${ }^{11} \mathrm{C}$-methionine PET and ${ }^{18} \mathrm{~F}$-FLT PET. ${ }^{11} \mathrm{C}$-methionine exhibited a slightly higher sensitivity $(87.8 \%)$ in tumor detection than ${ }^{18}$ F-FLT $(83.3 \%)$. All 
tumors were graded by the WHO grading system using surgical specimens, and the proliferation activity was determined by measuring the Ki-67 index obtained by immunohistochemical staining. ${ }^{18}$ F-FLT PET seemed superior in non-invasive tumor grading and assessment of proliferation activity. Ullrich et al. [64] evaluated 13 patients with newly diagnosed high-grade gliomas with ${ }^{18}$ F-FLT PET and ${ }^{11} \mathrm{C}$-methionine PET. They showed that ${ }^{18} \mathrm{~F}$-FLT uptake is useful for the in vivo assessment of tumor proliferation, whereas uptake ratios of ${ }^{11} \mathrm{C}$-methionine and ${ }^{18}$ F-FLT failed to correlate with the in vitro determined proliferation marker. Harris et al. [68] analyzed 21 patients with recurrent malignant gliomas who underwent bevacizumab treatment with ${ }^{18}$ F-FLT and showed that its uptake may be a valuable imaging biomarker for predicting progression-free survival. In the study by Jeong et al. [69], 20 patients with newly diagnosed gliomas were investigated with ${ }^{18} \mathrm{~F}$-FLT and ${ }^{18} \mathrm{~F}$-fluoroethyl-L-tyrosine $\left({ }^{18}\right.$ F-FET) PET before surgery. ${ }^{18}$ F-FLT PET detected all 17 high-grade gliomas but did not detect all three lowgrade gliomas. ${ }^{18}$ F-FET PET detected all 20 gliomas regardless of grading. Comparison with ${ }^{18}$ F-FLT PET showed that ${ }^{18}$ F-FET PET showed a higher sensitivity in the detection of gliomas, but it seemed that ${ }^{18}$ F-FLT PET was better than ${ }^{18} \mathrm{~F}$-FET PET for non-invasive grading and for predicting the prognosis of newly diagnosed gliomas. Miyake et al. [70] studied 54 patients affected by gliomas with ${ }^{18} \mathrm{~F}$-FDG, ${ }^{11} \mathrm{C}$-methionine, and ${ }^{18} \mathrm{~F}$-FLT. Among these 54 glioma cases, ${ }^{11} \mathrm{C}$-methionine accumulation was observed in 51 cases $(94.4 \%),{ }^{18}$ F-FLT accumulation in 50 cases $(92.6 \%)$, and ${ }^{18} \mathrm{~F}-\mathrm{FDG}$ accumulation in 27 cases $(50 \%)$. The three cases without ${ }^{11} \mathrm{C}$-methionine accumulation and the four cases without ${ }^{18} \mathrm{~F}$-FLT accumulation were grade-2 gliomas. All malignant gliomas (grades 3-4) showed accumulation in both studies.

Moreover, in the study by Saga et al. [60], ${ }^{18}$ F-FLT PET was performed in 25 patients with primary brain tumors and was found to be useful in evaluating the malignant grade and proliferation activity of these tumors; both $\mathrm{SUV}_{\text {max }}$ and tumor-to-normal brain uptake ratios significantly correlated with the malignant grade of brain gliomas. However, benign lesions showing BBB disruption could not be distinguished from malignant tumors and their presence therefore needed careful evaluation. Yamamoto et al. [61] retrospectively investigated 10 patients with recurrent glioblastoma multiforme who underwent ${ }^{18} \mathrm{~F}$ FLT PET and Gd-DTPA MR. ${ }^{18}$ F-FLT PET was useful for the detection of recurrent glioblastoma multiforme, but no clear relationship emerged between ${ }^{18}$ F-FLT accumulation and Gd-DTPA enhancement. Twenty-one patients with recurrent high-grade gliomas treated with bevacizumab and irinotecan were studied by Chen et al. [62]. ${ }^{18}$ F-FLT PET was performed within 1 week before the initiation of treatment, and at 1-2 and 6 weeks after start of treatment. Contrast and non-contrast brain MR images for treatment monitoring were acquired in all patients within 1 week before and at 6-week intervals after the start of treatment. A 6-month survival of $65 \%$ for glioblastoma patients was seen, and multivariate analysis demonstrated that ${ }^{18} \mathrm{~F}-\mathrm{FLT}$ response was the most powerful independent predictor of survival among all variables tested (age, number of recurrences, number of prior treatments, tumor grade, dexamethasone treatment, and time from radiation therapy). Baseline ${ }^{18}$ F-FLT SUVs were not predictive of patient survival and through receiver operating curve analysis, a metabolic response of greater than $25 \%$ reduction in tumor uptake was found to be the threshold with best predictive power for overall survival. Metabolic response was more powerful in predicting overall survival than anatomical imaging. In the study by Schwarzenberg et al. [71], 30 patients treated with bevacizumab combination therapy underwent ${ }^{18}$ F-FLT PET immediately before and at 2 and 6 weeks after the start of treatment, and results were compared to MR. Changes in tumor uptake were highly predictive of progression-free and overall survival in patients with recurrent malignant glioma on bevacizumab therapy, and ${ }^{18}$ F-FLT PET seemed more predictive of early treatment response than MR.

In the articles analyzed, ${ }^{18}$ F-FLT PET showed diagnostic performances that were better than those of ${ }^{18} \mathrm{~F}$-FDG PET, but lower than those of studies performed with ${ }^{11} \mathrm{C}$-methionine or ${ }^{18} \mathrm{~F}$-FET.

\section{Head and neck}

This is a very difficult and challenging area because of the anatomical and metabolic complexity of the structures present; moreover, the diagnostic setting is further complicated by a variety of significant anatomical and metabolic modifications occurring after surgery or radiotherapy, which are the main therapeutic tools. In this setting, ${ }^{18} \mathrm{~F}$ FDG shows limitations mainly due to functional activation of normal tissues and inflammation, and therefore, a tracer with fewer inflammatory pitfalls would be desirable.

The role of ${ }^{18}$ F-FLT in head and neck tumor imaging was analyzed in nine articles. Cobben et al. [72] evaluated 11 patients diagnosed or strongly suspected of having recurrent laryngeal cancer (LC) and 10 patients with histologically proven primary LC; all patients were staged by endoscopy and CT, and then submitted to ${ }^{18}$ F-FLT PET, ${ }^{18} \mathrm{~F}$-FDG PET, and biopsy of the larynx after imaging. ${ }^{18} \mathrm{~F}$ FDG PET and ${ }^{18}$ F-FLT PET detected LC correctly in $15 / 17$ patients. One lesion judged as positive on ${ }^{18} \mathrm{~F}$-FDG PET turned out to be normal tissue. Of two lesions judged positive on ${ }^{18} \mathrm{~F}$-FLT PET, one turned out to be inflammation and the other to be normal tissue. The authors 
concluded that the numbers of LCs detected with ${ }^{18} \mathrm{~F}$-FLT PET and ${ }^{18}$ F-FDG PET were equal. In the study by Troost et al. [73], 10 patients with newly diagnosed stage II-IV head and neck squamous cell cancers (HNSCCs) underwent ${ }^{18}$ F-FLT PET to determine the lymph-node status. The sensitivity, specificity, PPV, and NPV were 100, 16.7, 37.5 , and $100 \%$, respectively, due to the high rate of falsepositive findings. ${ }^{18} \mathrm{~F}$-FLT PET showed uptake in metastatic as well as in non-metastatic reactive lymph nodes. Because of the low specificity, ${ }^{18}$ F-FLT PET was judged unsuitable for assessment of pre-treatment lymph-node status. In the study by Linecker et al. [74], 20 patients with previously untreated lesions of the head and neck underwent PET scans with ${ }^{18}$ F-FLT and ${ }^{18}$ F-FDG, a CT and a biopsy. Nineteen patients had malignant tumors, and one a benign cystadenoma of the parotid gland. The sensitivity was $95 \%$ for both tracers. A significant correlation between both PET tracers and survival was detected, but no correlation between the amount of Ki-67 positive cells and ${ }^{18} \mathrm{~F}$-FLT, showing that the tracer does not provide additional visual information in comparison to ${ }^{18} \mathrm{~F}$-FDG. Been et al. [75] evaluated 14 patients with LC who underwent both ${ }^{18}$ F-FLT PET and ${ }^{18}$ F-FDG PET. They concluded that ${ }^{18}$ F-FLT PET was feasible in visualizing LC; the overall uptake was significantly lower as compared with ${ }^{18}$ F-FDG, but tumor-to-background ratios were comparable. In the study by Troost et al. [76], 10 patients with oropharyngeal tumor underwent an ${ }^{18} \mathrm{~F}$-FLT PET/CT scan before and in the second and fourth weeks of RT. All primary tumors and lymph-node metastases were visualized. In the primary tumors, the $\mathrm{SUV}_{\max }$ of the second ${ }^{18}$ F-FLT PET scan was already significantly decreased relative to the first scan, and the $\mathrm{SUV}_{\max }$ of the third scan was decreased even further. This study showed that ${ }^{18}$ F-FLT PET signal changes precede volumetric tumor response and that the tracer is therefore suitable for early response assessment. Troost et al. [77] aimed to validate ${ }^{18}$ F-FLT PET in squamous cell carcinomas of the oral cavity using immunohistochemical staining for the proliferation marker iododeoxyuridine and for TK-1. Seventeen patients underwent an ${ }^{18}$ F-FLT PET/ CT scan before surgery. All primary tumors were identified but with a large range in tracer uptake; there emerged only a weak correlation between ${ }^{18}$ F-FLT uptake and iododeoxyuridine staining intensity in oral cavity tumors. Hoshikawa et al. [78] evaluated 43 patients with HNSCCs. The mean SUV for ${ }^{18}$ F-FLT was significantly lower than that for ${ }^{18} \mathrm{~F}$-FDG and significantly higher in poorly than in well-differentiated tumors. ${ }^{18}$ F-FLT PET showed as high a sensitivity as ${ }^{18} \mathrm{~F}$-FDG PET for the detection of primary HNSCC lesions. Inubushi et al. [79] evaluated 13 patients with histologically proven head and neck mucosal malignant melanoma. ${ }^{18} \mathrm{~F}$-FLT PET/CT was performed before and 1 month after CIRT and was found to be useful for predicting the therapeutic outcome. Kishino et al. [80] studied 28 patients with HNSCCs during radiotherapy both with ${ }^{18} \mathrm{~F}$-FLT and ${ }^{18} \mathrm{~F}$-FDG. The specificity and overall AC of ${ }^{18} \mathrm{~F}$-FLT were significantly higher than those of ${ }^{18} \mathrm{~F}$ FDG both during and after radiotherapy and had the potential to predict therapeutic response and identify patients needing close follow-up to detect persistent or recurrent disease.

In the articles analyzed, despite the low number of studies available, ${ }^{18}$ F-FLT PET showed good diagnostic performances compared to ${ }^{18} \mathrm{~F}-\mathrm{FDG}$ in the absence of a documented superiority; the added value seemed to concern therapy response evaluation.

\section{Lympho-myeloproliferative diseases}

One of the most well-established diagnostic applications of ${ }^{18} \mathrm{~F}$-FDG in oncology is its use in the evaluation of lymphoproliferative diseases, especially Hodgkin's lymphoma and non-Hodgkin's lymphoma (NHL); consequently, a new tracer would really have to be more accurate than ${ }^{18} \mathrm{~F}$-FDG before replacing it.

The role of ${ }^{18} \mathrm{~F}$-FLT in the imaging of lympho-myeloproliferative diseases was analyzed in nine articles. Even though Agool et al. [81] demonstrated low ${ }^{18}$ F-FLT uptake in ${ }^{18}$ patients affected by myeloproliferative disorders, Buchmann et al. [6] showed that the use of ${ }^{18}$ F-FLT is feasible in NHL imaging and Buck et al. [7] showed it to offer advantages for the detection of lymphoma in the central nervous system in 34 patients, due to negligible background uptake of ${ }^{18} \mathrm{~F}$-FLT in the brain. In the study by Herrmann et al. [82], 22 patients with high-grade NHL scheduled to undergo first-line treatment received baseline imaging before and during therapy. An early decrease in uptake was demonstrated, and ${ }^{18}$ F-FLT was judged promising for early evaluation of drug effects in lymphoma. Kasper et al. [83] evaluated 48 patients affected by lymphoma (15 Hodgkin disease, 33 NHL) with residual masses $>2 \mathrm{~cm}$ examined with ${ }^{18} \mathrm{~F}$-FDG and ${ }^{18} \mathrm{~F}$-FLT. Overall survival for patients with a negative PET scan was significantly higher than for patients with positive PET, irrespective of the tracer used; no statistically significant differences emerged on comparing ${ }^{18} \mathrm{~F}-\mathrm{FDG} /{ }^{18} \mathrm{~F}-\mathrm{FLT}$ negative versus ${ }^{18} \mathrm{~F}-\mathrm{FDG}$ negative alone, and ${ }^{18} \mathrm{~F}-\mathrm{FDG}$ detected more lesions than ${ }^{18} \mathrm{~F}$-FLT did. No advantage of combined ${ }^{18} \mathrm{~F}$-FDG $/{ }^{18} \mathrm{~F}$-FLT studies over ${ }^{18} \mathrm{~F}$-FDG alone with respect to the prediction of survival was demonstrated. In the study by Buck et al. [84], 10 patients with acute myeloid leukemia (AML) underwent pre-therapeutic imaging with ${ }^{18} \mathrm{~F}$-FLT PET or ${ }^{18} \mathrm{~F}$-FLT PET/CT. Retention of ${ }^{18} \mathrm{~F}$-FLT was observed predominantly in bone marrow and spleen, and was significantly higher in AML patients than in controls. ${ }^{18}$ F-FLT uptake showed extramedullary 
manifestation sites in four patients, proven by other diagnostic procedures. ${ }^{18} \mathrm{~F}$-FLT was able to visualize extramedullary manifestation sites of AML and reflected disease activity even though the correlation between ${ }^{18} \mathrm{~F}$ FLT uptake in bone marrow and leukemic blast infiltration did not reach statistical significance. Herrmann et al. [85] evaluated eight untreated mantle cell lymphoma (MCL) patients. Correlation of mean ${ }^{18} \mathrm{~F}-\mathrm{FLT}$ and ${ }^{18} \mathrm{~F}$-FDG uptake in the hottest lesion to $\mathrm{Ki}-67$ immunostaining was performed. ${ }^{18}$ F-FLT showed a high sensitivity for MCL and a correlation with proliferation. Herrmann et al. [86] evaluated 66 patients with aggressive NHL treated with immuno-chemotherapy. All lymphoma lesions identified by a reference method $\left({ }^{18} \mathrm{~F}\right.$-FDG PET/CT or CT) showed increased focal tracer uptake and high ${ }^{18}$ F-FLT uptake was a negative predictor of response. Vanderhoek et al. [87] investigated eight patients with AML acquired at different time points during therapy and showed that imaging during induction chemotherapy may serve as an early biomarker of treatment response in AML.

In the articles analyzed, ${ }^{18}$ F-FLT PET did not seem able to replace ${ }^{18} \mathrm{~F}-\mathrm{FDG}$; given the negligible background uptake in the brain, a possible added value might be gained in detection of lymphoma in the central nervous system, which seemed to be an appropriate field of application.

\section{Breast}

The role of ${ }^{18} \mathrm{~F}$-FLT in breast tumor imaging was analyzed in six articles. Smyczek-Gargya et al. [88] evaluated 12 patients with primary breast cancer. The contrast between primary tumors or metastases and surrounding tissue was high in most cases, and ${ }^{18}$ F-FLT PET was judged a promising tool for imaging primary breast cancer and metastases. Been et al. [89] studied 10 patients, eight of whom showed ${ }^{18} \mathrm{~F}$-FLT uptake in the primary tumor, while two patients also showed additional lesions in the axilla. In the study by Pio et al. [90], 14 patients with metastatic breast cancer underwent ${ }^{18}$ F-FDG PET and ${ }^{18}$ F-FLT PET on two separate days within 1 week of each other before treatment, 2 weeks following the end of the first cycle, and following the final cycle. Nine patients completed the study. Following the first course of therapy, the percent change in average ${ }^{18} \mathrm{~F}$-FDG uptake demonstrated a loose correlation $(r=0.28 ; p=0.20)$ with the percent change in cancer antigen 27.29 (CA27.29) tumor marker levels after the entire therapy regimen. Early change in ${ }^{18} \mathrm{~F}$-FLT uptake exhibited a stronger correlation. Kenny et al. [91] evaluated 13 patients with ${ }^{18} \mathrm{~F}$-FLT PET to assess therapy response after chemotherapy and showed that it can detect changes in breast cancer proliferation at 1 week after 5-fluorouracil, epirubicin, and cyclophosphamide chemotherapy. Contractor et al. [92] evaluated 20 patients who underwent a baseline dynamic ${ }^{18}$ F-FLT PET scan followed by a similar post-treatment scan conducted approximately 14 days after the first or second cycle of docetaxel therapy; they showed that ${ }^{18}$ F-FLT PET was a promising imaging biomarker to detect early response. Moreover, Contractor et al. [93] performed a small pilot study to compare early changes in levels of circulatory tumor cells (CTCs) with changes in tumor proliferation, using imaging with ${ }^{18} \mathrm{~F}$-FLT in women with advanced breast cancer, before and during docetaxel therapy. In those individuals in whom they detected CTCs, a decrease in CTC count correlated with a decrease in ${ }^{18} \mathrm{~F}$ FLT signal, within 2 weeks.

In these very few articles analyzed, ${ }^{18}$ F-FLT PET seemed to be interesting mainly for therapy response evaluation.

\section{Miscellanea}

The remaining 11 articles evaluated the use of ${ }^{18} \mathrm{~F}$-FLT PET in various tumors not belonging to the above groups. Dittmann et al. [95] reported a high sensitivity in 16 patients with thoracic tumors (8 lung, 5 esophageal, 2 sarcoma and 1 Hodgkin's lymphoma). Cobben et al. [96] evaluated 19 patients with soft-tissue sarcoma (STS), identifying 20 tumors clearly visible with high contrast and reporting a sensitivity of $100 \%$. Been et al. [97] evaluated 10 patients with primary non-resectable STS of an extremity documenting high ${ }^{18}$ F-FLT uptake which was correlated with the mitotic index. In the study by Buck et al. [98], ${ }^{18}$ F-FLT PET was performed in 22 patients with established or suspected soft or bone tissue lesions; ${ }^{18} \mathrm{~F}$ FDG PET was performed in 15 patients. ${ }^{18} \mathrm{~F}$-FLT PET detected all malignant bone or soft tissue tumors and correlated significantly with the tumor grade while ${ }^{18} \mathrm{~F}-\mathrm{FDG}$ did not. ${ }^{18}$ F-FLT was judged superior for non-invasive grading of sarcomas. In the study by Benz et al. [103], 20 patients with biopsy-proven high-grade STS underwent ${ }^{18}$ F-FLT PET/CT imaging before and after neoadjuvant therapy. Marked reductions in ${ }^{18} \mathrm{~F}$-FLT tumor uptake in response to neoadjuvant treatment were observed in most patients, but these reductions were not specific for histopathologic response to neoadjuvant therapy. Furthermore, post-treatment ${ }^{18} \mathrm{~F}$-FLT uptake was unrelated to tumor proliferation by Ki-67 and TK-1 staining. Response assessment based on ${ }^{18} \mathrm{~F}$-FLT PET was not found to be advantageous over ${ }^{18}$ F-FDG. Cobben et al. [94] and Ribas et al. [100] showed promising results in patients with stage III or advanced melanoma; Cobben et al. studied 10 patients and reported that all locoregional lymph-node metastases were correctly visualized by ${ }^{18} \mathrm{~F}$-FLT PET with a sensitivity of $88 \%$; Ribas et al. showed that ${ }^{18}$ F-FLT allowed mapping and non-invasive imaging of cell proliferation in secondary lymphoid organs in 12 patients. In the 
study by Pfannenberg et al. [99], 11 patients with metastatic germ cell tumors were examined with ${ }^{18} \mathrm{~F}-\mathrm{FDG}$ PET/CT and ${ }^{18}$ F-FLT PET/CT before chemotherapy, after the first cycle, and 3 weeks after completion. The sensitivity, specificity, PPV, and NPV for detection of viable tumor after one cycle of chemotherapy were $60,33,43$, and $50 \%$, respectively, for ${ }^{18} \mathrm{~F}-\mathrm{FDG}$ and $60,80,75$, and $67 \%$, respectively, for ${ }^{18} \mathrm{~F}$-FLT. The respective values after the end of chemotherapy were $20,100,100$, and $60 \%$ for ${ }^{18} \mathrm{~F}$ FDG and $0,100,0$, and $50 \%$ for ${ }^{18}$ F-FLT. PET-negative residual masses after chemotherapy of metastatic germ cell tumors still required resection, since the low NPV of ${ }^{18} \mathrm{~F}$ FDG for viable tumor could not be improved by application of ${ }^{18}$ F-FLT. Richard et al. [102] evaluated six patients with suspected new and recurrent ovarian carcinoma with ${ }^{18}$ F-FLT and showed that non-invasive imaging with ${ }^{18}$ FLT-PET is promising and supports the need for further studies in larger groups of patients. Yamane et al. [104] studied 15 patients with uterine cancers submitted to both ${ }^{18}$ F-FLT and ${ }^{18}$ F-FDG PET. They found ${ }^{18}$ F-FLT to be superior in differentiating malignant from benign leiomyoma. Giammarile et al. [101] evaluated, with ${ }^{18}$ F-FDG and ${ }^{18}$ F-FLT PET, 10 patients with locally advanced or metastasized, well-differentiated gastro-entero-pancreatic neuroendocrine tumors. No positive case was identified by ${ }^{18} \mathrm{~F}$-FLT in either the primary or the metastatic tumor site, whatever the status of patients; this finding, probably a reflection of the slow proliferation rate of tumors, suggests that ${ }^{18} \mathrm{~F}$-FLT was not a suitable tracer.

\section{Conclusions}

In conclusion, no high quality evidence could be derived on the role of ${ }^{18}$ F-FLT PET in oncology imaging because of the extreme heterogeneity between the studies (with regard to the tumors evaluated, the reasons for performing the evaluations, and the devices and methodologies used), the limited number of studies for each tumor, and the very low number of patients enrolled in each study. Despite these limitations, this comprehensive review of the literature reveals published results which suggest that this tracer has a promising role in oncology imaging, especially in (1) assessing response to treatment or therapy monitoring. Since no uptake or lower uptake than other tracers (especially ${ }^{18} \mathrm{~F}$-FDG) is expected in inflammatory cells, ${ }^{18} \mathrm{~F}$-FLT could be very useful for therapy response evaluation allowing earlier identification of non-responders who could be switched to second-line treatment; in this scenario, it represents a highly promising method contributing to the individualization of cancer therapy; (2) tumor grading. ${ }^{18} \mathrm{~F}-\mathrm{FLT}$ can be seen as a proliferation tracer because it is phosphorylated by TK-1 which is commonly higher in malignant lesions making it more tumor-specific than other tracers; moreover, the strong correlations between ${ }^{18} \mathrm{~F}$-FLT uptake and histopathological proliferation markers can serve as a non-invasive tool for establishing tumor grade; (3) evaluating brain malignancies. In this setting, the low background uptake, probably due to the slow proliferation rate of normal tissue, is an advantage even though it will be difficult for this tracer to beat ${ }^{18} \mathrm{~F}$-FET and ${ }^{18} \mathrm{~F}$-DOPA.

Further studies are needed to confirm these preliminary results, and larger trials are desirable to establish the definitive diagnostic role of ${ }^{18}$ F-FLT in oncological clinical practice, considering, its usefulness in relation to and in comparison with the well-established ${ }^{18}$ F-FDG, its importance in terms of cost-effectiveness and its correct position in the diagnostic flow-chart for each tumor type.

Conflict of interest The authors declare that they have no conflict of interest.

\section{References}

1. Rasey JS, Grierson JR, Wiens LW, Kolb PD, Schwartz JL (2002) Validation of FLT uptake as a measure of thymidine kinase-1 activity in A549 carcinoma cells. J Nucl Med 43:1210-1217

2. Flexner C, van der Horst C, Jacobson MA, Powderly W, Duncanson F, Ganes D, Barditch-Crovo PA, Petty BG, Baron PA, Armstrong D (1994) Relationship between plasma concentrations of $3^{\prime}$-deoxy-3'-fluorothymidine (alovudine) and antiretroviral activity in two concentration-controlled trials. J Infect Dis 170:1394-1403

3. Shields AF, Grierson JR, Dohmen BM, Machulla HJ, Stayanoff JC, Lawhorn-Crews JM, Obradovich JE, Muzik O, Mangner TJ (1998) Imaging proliferation in vivo with [F-18]FLT and positron emission tomography. Nat Med 4:1334-1336

4. Shields AF (2003) PET imaging with 18F-FLT and thymidine analogs: promise and pitfalls. J Nucl Med 44:1432-1434

5. Bading JR, Shields AF (2008) Imaging of cell proliferation: status and prospects. J Nucl Med 49(Suppl 2):64S-80S

6. Buchmann I, Neumaier B, Schreckenberger M, Reske S (2004) [18F $] 3^{\prime}$-deoxy-3'-fluorothymidine-PET in NHL patients: wholebody biodistribution and imaging of lymphoma manifestationsa pilot study. Cancer Biother Radiopharm 19:436-442

7. Buck AK, Bommer M, Stilgenbauer S, Juweid M, Glatting G, Schirrmeister H, Mattfeldt T, Tepsic D, Bunjes D, Mottaghy FM, Krause BJ, Neumaier B, Döhner H, Möller P, Reske SN (2006) Molecular imaging of proliferation in malignant lymphoma. Cancer Res 66:11055-11061

8. Alauddin MM (2012) Positron emission tomography (PET) imaging with $18 \mathrm{~F}$-based radiotracers. Am J Nucl Med Mol Imaging 2:55-76

9. Pascali C, Bogni A, Fugazza L, Cucchi C, Crispu O, Laera L, Iwata R, Maiocchi G, Crippa F, Bombardieri E (2012) Simple preparation and purification of ethanol-free solutions of $3^{\prime}$-deoxy-3'-[18F]fluorothymidine by means of disposable solidphase extraction cartridges. Nucl Med Biol 39:540-550

10. Wilson IK, Chatterjee S, Wolf W (1991) Synthesis of $3^{\prime}$-fluoro$3^{\prime}$-deoxythymidine and studies of its $18 \mathrm{~F}$-radiolabeling, as a tracer for the non-invasive monitoring of the biodistribution of drugs against AIDS. J Fluorine Chem 55:283-289

11. Machulla HJ, Blocher A, Kuntzsch M, Piert M, Wei R, Grierson JR (2000) Simplified labeling approach for synthesizing 
$3^{\prime}$-deoxy-3'-18Ffluorothymidine (18F-FLT). J Radioanal Nucl Chem 243:843-846

12. Grierson JR, Shields AF (2000) Radiosynthesis of $3^{\prime}$-deoxy-3'18 F-fluorothymidine: 18F-FLT for imaging of cellular proliferation in vivo. Nucl Med Biol 27:143-156

13. Oh SJ, Mosdzianowski C, Chi DY, Kim JU, Kang SH, Ryu JS, Yeo JS, Moon DH (2004) Fully automated synthesis system of 3'-deoxy-3'-18Ffluorothymidine. Nucl Med Biol 31:803-809

14. Reischl G, Blocker A, Wei R, Ehrlichmann W, Kuntzsch M, Solbach C, Dohmen BM, Machulla HJ (2006) Simplified, automated synthesis of $3^{\prime}-18 \mathrm{~F}$-fluoro- $3^{\prime}$-deoxy-thymidine $(18 \mathrm{~F}$ FLT) and simple method for metabolite analysis in plasma. Radiochim Acta 94:447-458

15. Teng B, Wang S, Fu Z, Dang Y, Wu Z, Liu L (2006) Semiautomatic synthesis of $3^{\prime}$-deoxy-3'-18Ffluorothymidine using three precursors. Appl Radiat Isot 64:187-193

16. Nandy SK, Rajan MGR (2010) Fully automated and simplified radiosynthesis of $[18 \mathrm{~F}]-3^{\prime}$-deoxy- $3^{\prime}$-fluorothymidine using anhydro precursor and single neutral alumina column purification. J Radioanal Nucl Chem 283:741-748

17. Tang G, Tang X, Wen F, Wang M, Li B (2010) A facile and rapid automated synthesis of $3^{\prime}$-deoxy-3'-[18F]fluorothymidine. Appl Radiat Isot 68:1734-1739

18. Barthel H, Cleij MC, Collingridge DR, Hutchinson OC, Osman S, He Q, Luthra SK, Brady F, Price PM, Aboagye EO (2003) 3'deoxy- $3^{\prime}-[18 \mathrm{~F}]$ fluorothymidine as a new marker for monitoring tumor response to antiproliferative therapy in vivo with positron emission tomography. Cancer Res 63:3791-3798

19. Vesselle H, Grierson J, Muzi M, Pugsley JM, Schmidt RA, Rabinowitz P, Peterson LM, Vallières E, Wood DE (2002) In vivo validation of $3^{\prime}$ deoxy- $3^{\prime}-[(18) F]$ fluorothymidine ([(18)F]FLT) as a proliferation imaging tracer in humans: correlation of [(18)F]FLT uptake by positron emission tomography with $\mathrm{Ki}-67$ immunohistochemistry and flow cytometry in human lung tumors. Clin Cancer Res 8:3315-3323

20. Buck AK, Schirrmeister H, Hetzel M, Von Der Heide M, Halter G, Glatting G, Mattfeldt T, Liewald F, Reske SN, Neumaier B (2002) 3-deoxy-3-[(18)F]fluorothymidine-positron emission tomography for noninvasive assessment of proliferation in pulmonary nodules. Cancer Res 62:3331-3334

21. Buck AK, Halter G, Schirrmeister H, Kotzerke J, Wurziger I, Glatting G, Mattfeldt T, Neumaier B, Reske SN, Hetzel M (2003) Imaging proliferation in lung tumors with PET: 18F-FLT versus 18F-FDG. J Nucl Med 44:1426-1431

22. Cobben DC, Elsinga PH, Hoekstra HJ, Suurmeijer AJ, Vaalburg W, Maas B, Jager PL, Groen HM (2004) Is 18F-3'-fluoro-3'deoxy-L-thymidine useful for the staging and restaging of nonsmall cell lung cancer? J Nucl Med 45:1677-1682

23. Buck AK, Hetzel M, Schirrmeister H, Halter G, Möller P, Kratochwil C, Wahl A, Glatting G, Mottaghy FM, Mattfeldt T, Neumaier B, Reske SN (2005) Clinical relevance of imaging proliferative activity in lung nodules. Eur J Nucl Med Mol Imaging 32:525-533

24. Yap CS, Czernin J, Fishbein MC, Cameron RB, Schiepers C, Phelps ME, Weber WA (2006) Evaluation of thoracic tumours with 18F-fluorothymidine and 18F-fluorodeoxyglucose-positron emission tomography. Chest 129:393-401

25. Yamamoto Y, Nishiyama Y, Ishikawa S, Nakano J, Chang SS, Bandoh S, Kanaji N, Haba R, Kushida Y, Ohkawa M (2007) Correlation of 18F-FLT and 18F-FDG uptake on PET with Ki67 immunohistochemistry in non-small cell lung cancer. Eur J Nucl Med Mol Imaging 34:1610-1616

26. Sohn HJ, Yang YJ, Ryu JS, Oh SJ, Im KC, Moon DH, Lee DH, Suh C, Lee JS, Kim SW (2008) [18F]Fluorothymidine positron emission tomography before and 7 days after gefitinib treatment predicts response in patients with advanced adenocarcinoma of the lung. Clin Cancer Res 14:7423-7429
27. Tian J, Yang X, Yu L, Chen P, Xin J, Ma L, Feng H, Tan Y, Zhao Z, $\mathrm{Wu}$ W (2008) A multicenter clinical trial on the diagnostic value of dual-tracer PET/CT in pulmonary lesions using $3^{\prime}$-deoxy-3'-18Ffluorothymidine and 18F-FDG. J Nucl Med 49:186-194

28. Yamamoto Y, Nishiyama Y, Ishikawa S, Gotoh M, Bandoh S, Kanaji N, Asakura M, Ohkawa M (2008) 3'-Deoxy-3'-18F-fluorothymidine as a proliferation imaging tracer for diagnosis of lung tumours: comparison with 2-deoxy-2-18f-fluoro-D-glucose. J Comput Assist Tomogr 32:432-437

29. Yamamoto Y, Nishiyama Y, Kimura N, Ishikawa S, Okuda M, Bandoh S, Kanaji N, Asakura M, Ohkawa M (2008) Comparison of (18)F-FLT PET and (18)F-FDG PET for preoperative staging in non-small cell lung cancer. Eur $\mathrm{J}$ Nucl Med Mol Imaging 35:236-245

30. Everitt S, Hicks RJ, Ball D, Kron T, Schneider-Kolsky M, Walter T, Binns D, Mac Manus M (2009) Imaging cellular proliferation during chemo-radiotherapy: a pilot study of serial 18F-FLT positron emission tomography/computed tomography imaging for non-small-cell lung cancer. Int J Radiat Oncol Biol Phys 75:1098-1104

31. Yang W, Zhang Y, Fu Z, Yu J, Sun X, Mu D, Han A (2010) Imaging of proliferation with $18 \mathrm{~F}-\mathrm{FLT}$ PET/CT versus $18 \mathrm{~F}$ FDG PET/CT in non-small-cell lung cancer. Eur $\mathrm{J}$ Nucl Med Mol Imaging 37:1291-1299

32. Kahraman D, Scheffler M, Zander T, Nogova L, Lammertsma AA, Boellaard R, Neumaier B, Ullrich RT, Holstein A, Dietlein M, Wolf J, Kobe C (2011) Quantitative analysis of response to treatment with erlotinib in advanced non-small cell lung cancer using 18F-FDG and $3^{\prime}$-deoxy-3'-18F-fluorothymidine PET. J Nucl Med 52:1871-1877

33. Mileshkin L, Hicks RJ, Hughes BG, Mitchell PL, Charu V, Gitlitz BJ, Macfarlane D, Solomon B, Amler LC, Yu W, Pirzkall A, Fine BM (2011) Changes in 18F-fluorodeoxyglucose and 18F-fluorodeoxythymidine positron emission tomography imaging in patients with non-small cell lung cancer treated with erlotinib. Clin Cancer Res 17:3304-3315

34. Saga T, Koizumi M, Inubushi M, Yoshikawa K, Tanimoto K, Fukumura T, Miyamoto T, Nakajima M, Yamamoto N, Baba M (2011) PET/CT with $3^{\prime}$-deoxy-3'-[18F]fluorothymidine for lung cancer patients receiving carbon-ion radiotherapy. Nucl Med Commun 32:348-355

35. Vera P, Bohn P, Edet-Sanson A, Salles A, Hapdey S, Gardin I, Ménard JF, Modzelewski R, Thiberville L, Dubray B (2011) Simultaneous positron emission tomography (PET) assessment of metabolism with 18-fluoro-2-deoxy-D-glucose (FDG), proliferation with $18 \mathrm{~F}$-fluoro-thymidine (FLT), and hypoxia with 18-fluoro-misonidazole (F-miso) before and during radiotherapy in patients with non-small-cell lung cancer (NSCLC): a pilot study. Radiother Oncol 98:109-116

36. Xu B, Guan Z, Liu C, Wang R, Yin D, Zhang J, Chen Y, Yao S, Shao M, Wang H, Tian J (2011) Can multimodality imaging using 18F-FDG/18F-FLT PET/CT benefit the diagnosis and management of patients with pulmonary lesions? Eur J Nucl Med Mol Imaging 38:285-292

37. Zander T, Scheffler M, Nogova L, Kobe C, Engel-Riedel W, Hellmich M, Papachristou I, Toepelt K, Draube A, Heukamp L, Buettner R, Ko YD, Ullrich RT, Smit E, Boellaard R, Lammertsma AA, Hallek M, Jacobs AH, Schlesinger A, Schulte K, Querings S, Stoelben E, Neumaier B, Thomas RK, Dietlein M, Wolf J (2011) Early prediction of nonprogression in advanced non-small-cell lung cancer treated with erlotinib by using [(18)F]fluorodeoxyglucose and [(18)F]fluorothymidine positron emission tomography. J Clin Oncol 29:1701-1708

38. Kobe C, Scheffler M, Holstein A, Zander T, Nogova L, Lammertsma AA, Boellaard R, Neumaier B, Ullrich RT, Dietlein M, Wolf J, Kahraman D (2012) Predictive value of early and late 
residual $18 \mathrm{~F}$-fluorodeoxyglucose and $18 \mathrm{~F}$-fluorothymidine uptake using different SUV measurements in patients with nonsmall-cell lung cancer treated with erlotinib. Eur J Nucl Med Mol Imaging 39:1117-1127

39. Yang W, Zhang Y, Fu Z, Sun X, Mu D, Yu J (2012) Imaging proliferation of 18F-FLT PET/CT correlated with the expression of microvessel density of tumour tissue in non-small-cell lung cancer. Eur J Nucl Med Mol Imaging 39:1289-1296

40. Francis DL, Freeman A, Visvikis D, Costa DC, Luthra SK, Novelli M, Taylor I, Ell PJ (2003) In vivo imaging of cellular proliferation in colorectal cancer using positron emission tomography. Gut 52:1602-1606

41. Francis DL, Visvikis D, Costa DC, Arulampalam TH, Townsend C, Luthra SK, Taylor I, Ell PJ (2003) Potential impact of [18F] $3^{\prime}$-deoxy-3'-fluorothymidine versus [18F]fluoro-2-deoxyD-glucose in positron emission tomography for colorectal cancer. Eur J Nucl Med Mol Imaging 30:988-994

42. van Westreenen HL, Cobben DC, Jager PL, van Dullemen HM, Wesseling J, Elsinga PH, Plukker JT (2005) Comparison of 18FFLT PET and 18F-FDG PET in esophageal cancer. J Nucl Med 46:400-404

43. Herrmann K, Ott K, Buck AK, Lordick F, Wilhelm D, Souvatzoglou $\mathrm{M}$, Becker K, Schuster T, Wester HJ, Siewert JR, Schwaiger M, Krause BJ (2007) Imaging gastric cancer with PET and the radiotracers 18F-FLT and 18F-FDG: a comparative analysis. J Nucl Med 48:1945-1950

44. Wieder HA, Geinitz H, Rosenberg R, Lordick F, Becker K, Stahl A, Rummeny E, Siewert JR, Schwaiger M, Stollfuss J (2007) PET imaging with $[18 \mathrm{~F}] 3^{\prime}$-deoxy- $3^{\prime}$-fluorothymidine for prediction of response to neoadjuvant treatment in patients with rectal cancer. Eur J Nucl Med Mol Imaging 34:878-883

45. Herrmann K, Eckel F, Schmidt S, Scheidhauer K, Krause BJ, Kleeff J, Schuster T, Wester HJ, Friess H, Schmid RM, Schwaiger M, Buck AK (2008) In vivo characterization of proliferation for discriminating cancer from pancreatic pseudotumours. J Nucl Med 49:1437-1444

46. Quon A, Chang ST, Chin F, Kamaya A, Dick DW, Loo BW Jr, Gambhir SS, Koong AC (2008) Initial evaluation of 18F-fluorothymidine (FLT) PET/CT scanning for primary pancreatic cancer. Eur J Nucl Med Mol Imaging 35:527-531

47. Eckel F, Herrmann K, Schmidt S, Hillerer C, Wieder HA, Krause BJ, Schuster T, Langer R, Wester HJ, Schmid RM, Schwaiger M, Buck AK (2009) Imaging of proliferation in hepatocellular carcinoma with the in vivo marker $18 \mathrm{~F}$-fluorothymidine. J Nucl Med 50:1441-1447

48. Kameyama R, Yamamoto Y, Izuishi K, Takebayashi R, Hagiike M, Murota M, Kaji M, Haba R, Nishiyama Y (2009) Detection of gastric cancer using 18F-FLT PET: comparison with 18FFDG PET. Eur J Nucl Med Mol Imaging 36:382-388

49. Yamamoto Y, Kameyama R, Izuishi K, Takebayashi R, Hagiike M, Asakura M, Haba R, Nishiyama Y (2009) Detection of colorectal cancer using 18F-FLT PET: comparison with ${ }^{18} \mathrm{~F}-$ FDG PET. Nucl Med Commun 30:841-845

50. Yue J, Chen L, Cabrera AR, Sun X, Zhao S, Zheng F, Han A, Zheng J, Teng X, Ma L, Ma Y, Han D, Zhao X, Mu D, Yu J, Li Y (2010) Measuring tumour cell proliferation with 18F-FLT PET during radiotherapy of esophageal squamous cell carcinoma: a pilot clinical study. J Nucl Med 51:528-534

51. Kameyama R, Yamamoto Y, Izuishi K, Sano T, Nishiyama Y (2011) Correlation of 18F-FLT uptake with equilibrative nucleoside transporter-1 and thymidine kinase- 1 expressions in gastrointestinal cancer. Nucl Med Commun 32:460-465

52. Muijs CT, Beukema JC, Widder J, van den Bergh AC, Havenga K, Pruim J, Langendijk JA (2011) 18F-FLT-PET for detection of rectal cancer. Radiother Oncol 98:357-359
53. Ott K, Herrmann K, Schuster T, Langer R, Becker K, Wieder HA, Wester HJ, Siewert JR, zum Büschenfelde CM, Buck AK, Wilhelm D, Ebert MP, Peschel C, Schwaiger M, Lordick F, Krause BJ (2011) Molecular imaging of proliferation and glucose utilization: utility for monitoring response and prognosis after neoadjuvant therapy in locally advanced gastric cancer. Ann Surg Oncol 18:3316-3323

54. Dehdashti F, Grigsby PW, Myerson RJ, Nalbantoglu I, Ma C, Siegel BA (2012) Positron emission tomography with [(18)F]$3^{\prime}$-deoxy-3'fluorothymidine (FLT) as a predictor of outcome in patients with locally advanced resectable rectal cancer: a pilot study. Mol Imaging Biol. doi:10.1007/s11307-012-0566-y

55. Han D, Yu J, Zhong X, Fu Z, Mu D, Zhang B, Xu G, Yang W, Zhao S (2012) Comparison of the diagnostic value of 3-deoxy-3(18) F-fluorothymidine and (18) F-fluorodeoxyglucose positron emission tomography/computed tomography in the assessment of regional lymph node in thoracic esophageal squamous cell carcinoma: a pilot study. Dis Esophagus 25:416-426

56. Herrmann K, Erkan M, Dobritz M, Schuster T, Siveke JT, Beer AJ, Wester HJ, Schmid RM, Friess H, Schwaiger M, Kleeff J, Buck AK (2012) Comparison of $3^{\prime}$-deoxy- $3^{\prime}-\left[{ }^{18}\right.$ F $]$ fluorothymidine positron emission tomography (FLT PET) and FDG PET/ $\mathrm{CT}$ for the detection and characterization of pancreatic tumours. Eur J Nucl Med Mol Imaging 39:846-851

57. Chen W, Cloughesy T, Kamdar N, Satyamurthy N, Bergsneider M, Liau L, Mischel P, Czernin J, Phelps ME, Silverman DH (2005) Imaging proliferation in brain tumors with 18F-FLT PET: comparison with 18F-FDG. J Nucl Med 46:945-952

58. Choi SJ, Kim JS, Kim JH, Oh SJ, Lee JG, Kim CJ, Ra YS, Yeo JS, Ryu JS, Moon DH (2005) [18F]3'-deoxy-3'-fluorothymidine PET for the diagnosis and grading of brain tumours. Eur J Nucl Med Mol Imaging 32:653-659

59. Jacobs AH, Thomas A, Kracht LW, Li H, Dittmar C, Garlip G, Galldiks N, Klein JC, Sobesky J, Hilker R, Vollmar S, Herholz K, Wienhard K, Heiss WD (2005) 18F-fluoro-L-thymidine and $11 \mathrm{C}$-methylmethionine as markers of increased transport and proliferation in brain tumours. J Nucl Med 46:1948-1958

60. Saga T, Kawashima H, Araki N, Takahashi JA, Nakashima Y, Higashi T, Oya N, Mukai T, Hojo M, Hashimoto N, Manabe T, Hiraoka M, Togashi K (2006) Evaluation of primary brain tumours with FLT-PET: usefulness and limitations. Clin Nucl Med 31:774-780

61. Yamamoto Y, Wong TZ, Turkington TG, Hawk TC, Reardon DA, Coleman RE (2006) 3'-Deoxy-3'-[F-18]fluorothymidine positron emission tomography in patients with recurrent glioblastoma multiforme: comparison with Gd-DTPA enhanced magnetic resonance imaging. Mol Imaging Biol 8:340-347

62. Chen W, Delaloye S, Silverman DH, Geist C, Czernin J, Sayre J, Satyamurthy N, Pope W, Lai A, Phelps ME, Cloughesy T (2007) Predicting treatment response of malignant gliomas to bevacizumab and irinotecan by imaging proliferation with $[18 \mathrm{~F}]$ fluorothymidine positron emission tomography: a pilot study. J Clin Oncol 25:4714-4721

63. Hatakeyama T, Kawai N, Nishiyama Y, Yamamoto Y, Sasakawa Y, Ichikawa T, Tamiya T (2008) 11C-methionine (MET) and 18F-fluorothymidine (FLT) PET in patients with newly diagnosed glioma. Eur J Nucl Med Mol Imaging 35:2009-2017

64. Ullrich R, Backes H, Li H, Kracht L, Miletic H, Kesper K, Neumaier B, Heiss WD, Wienhard K, Jacobs AH (2008) Glioma proliferation as assessed by $3^{\prime}$-fluoro- $3^{\prime}$-deoxy-L-thymidine positron emission tomography in patients with newly diagnosed high-grade glioma. Clin Cancer Res 14:2049-2055

65. Tripathi M, Sharma R, D’Souza M, Jaimini A, Panwar P, Varshney R, Datta A, Kumar N, Garg G, Singh D, Grover RK, Mishra AK, Mondal A (2009) Comparative evaluation of F-18 
FDOPA, F-18 FDG, and F-18 FLT-PET/CT for metabolic imaging of low grade gliomas. Clin Nucl Med 34:878-883

66. Hong IK, Kim JH, Ra YS, Kwon do H, Oh SJ, Kim JS (2011) Diagnostic usefulness of $3^{\prime}$-deoxy- $3^{\prime}-[18 \mathrm{~F}]$ fluorothymidine positron emission tomography in recurrent brain tumour. J Comput Assist Tomogr 35:679-684

67. Enslow MS, Zollinger LV, Morton KA, Butterfield RI, Kadrmas DJ, Christian PE, Boucher KM, Heilbrun ME, Jensen RL, Hoffman JM (2012) Comparison of 18F-fluorodeoxyglucose and 18F-fluorothymidine PET in differentiating radiation necrosis from recurrent glioma. Clin Nucl Med 37:854-861

68. Harris RJ, Cloughesy TF, Pope WB, Nghiemphu PL, Lai A, Zaw T, Czernin J, Phelps ME, Chen W, Ellingson BM (2012) 18FFDOPA and 18F-FLT positron emission tomography parametric response maps predict response in recurrent malignant gliomas treated with bevacizumab. Neuro Oncol 14:1079-1089

69. Jeong SY, Lim SM (2012) Comparison of $3^{\prime}$-deoxy-3'$[(18)$ F $]$ fluorothymidine PET and $O-(2-[(18) F]$ fluoroethyl)-Ltyrosine PET in patients with newly diagnosed glioma. Nucl Med Biol. doi:10.1016/j.nucmedbio.2012.02.009

70. Miyake K, Shinomiya A, Okada M, Hatakeyama T, Kawai N, Tamiya T (2012) Usefulness of FDG, MET and FLT-PET studies for the management of human gliomas. J Biomed Biotechnol 2012:205818

71. Schwarzenberg J, Czernin J, Cloughesy TF, Ellingson BM, Pope WB, Geist C, Dahlbom M, Silverman DH, Satyamurthy N, Phelps ME, Chen W (2012) 3'-deoxy-3'-18F-fluorothymidine PET and MRI for early survival predictions in patients with recurrent malignant glioma treated with bevacizumab. J Nucl Med 53:29-36

72. Cobben DC, van der Laan BF, Maas B, Vaalburg W, Suurmeijer AJ, Hoekstra HJ, Jager PL, Elsinga PH (2004) 18F-FLT PET for visualization of laryngeal cancer: comparison with $18 \mathrm{~F}-\mathrm{FDG}$ PET. J Nucl Med 45:226-231

73. Troost EG, Vogel WV, Merkx MA, Slootweg PJ, Marres HA, Peeters WJ, Bussink J, van der Kogel AJ, Oyen WJ, Kaanders JH (2007) 18F-FLT PET does not discriminate between reactive and metastatic lymph nodes in primary head and neck cancer patients. J Nucl Med 48:726-735

74. Linecker A, Kermer C, Sulzbacher I, Angelberger P, Kletter K, Dudczak R, Ewers R, Becherer A (2008) Uptake of (18)F-FLT and (18)F-FDG in primary head and neck cancer correlates with survival. Nuklearmedizin 47:80-85 (quiz N12)

75. Been LB, Hoekstra HJ, Suurmeijer AJ, Jager PL, van der Laan BF, Elsinga PH (2009) [18F]FLT-PET and [18F]FDG-PET in the evaluation of radiotherapy for laryngeal cancer. Oral Oncol 45:e211-e215

76. Troost EG, Bussink J, Hoffmann AL, Boerman OC, Oyen WJ, Kaanders JH (2010) 18F-FLT PET/CT for early response monitoring and dose escalation in oropharyngeal tumours. J Nucl Med 51:866-874

77. Troost EG, Bussink J, Slootweg PJ, Peeters WJ, Merkx MA, van der Kogel AJ, Oyen WJ, Kaanders JH (2010) Histopathologic validation of $3^{\prime}$-deoxy-3'-18F-fluorothymidine PET in squamous cell carcinoma of the oral cavity. J Nucl Med 51:713-719

78. Hoshikawa H, Nishiyama Y, Kishino T, Yamamoto Y, Haba R, Mori N (2011) Comparison of FLT-PET and FDG-PET for visualization of head and neck squamous cell cancers. Mol Imaging Biol 13:172-177

79. Inubushi M, Saga T, Koizumi M, Takagi R, Hasegawa A, Koto M, Wakatuki M, Morikawa T, Yoshikawa K, Tanimoto K, Fukumura T, Yamada S, Kamada T (2012) Predictive value of 3'deoxy- $3^{\prime}-[(18)$ F $]$ fluorothymidine positron emission tomography/ computed tomography for outcome of carbon ion radiotherapy in patients with head and neck mucosal malignant melanoma. Ann Nucl Med. doi:10.1007/s12149-012-0652-x
80. Kishino T, Hoshikawa H, Nishiyama Y, Yamamoto Y, Mori N (2012) Usefulness of 3'-Deoxy-3'-18F-fluorothymidine PET for predicting early response to chemoradiotherapy in head and neck cancer. J Nucl Med. doi:10.2967/jnumed.111.099200

81. Agool A, Schot BW, Jager PL, Vellenga E (2006) 18F-FLT PET in hematologic disorders: a novel technique to analyze the bone marrow compartment. J Nucl Med 47:1592-1598

82. Herrmann K, Wieder HA, Buck AK, Schöffel M, Krause BJ, Fend F, Schuster T, Meyer zum Büschenfelde C, Wester HJ, Duyster J, Peschel C, Schwaiger M, Dechow T (2007) Early response assessment using $3^{\prime}$-deoxy- $3^{\prime}$-[18F]fluorothymidinepositron emission tomography in high-grade non-Hodgkin's lymphoma. Clin Cancer Res 13:3552-3558

83. Kasper B, Egerer G, Gronkowski M, Haufe S, Lehnert T, Eisenhut M, Mechtersheimer G, Ho AD, Haberkorn U (2007) Functional diagnosis of residual lymphomas after radiochemotherapy with positron emission tomography comparing FDGand FLT-PET. Leuk Lymphoma 48:746-753

84. Buck AK, Bommer M, Juweid ME, Glatting G, Stilgenbauer S, Mottaghy FM, Schulz M, Kull T, Bunjes D, Möller P, Döhner H, Reske SN (2008) First demonstration of leukemia imaging with the proliferation marker 18F-fluorodeoxythymidine. J Nucl Med 49:1756-1762

85. Herrmann K, Buck AK, Schuster T, Rudelius M, Wester HJ, Graf N, Scheuerer C, Peschel C, Schwaiger M, Dechow T, Keller U (2011) A pilot study to evaluate $3^{\prime}$-deoxy- $3^{\prime}$-18F-fluorothymidine pet for initial and early response imaging in mantle cell lymphoma. J Nucl Med 52:1898-1902

86. Herrmann K, Buck AK, Schuster T, Junger A, Wieder HA, Graf N, Ringshausen I, Rudelius M, Wester HJ, Schwaiger M, Keller U, Dechow T (2011) Predictive value of initial 18F-FLT uptake in patients with aggressive non-Hodgkin lymphoma receiving R-CHOP treatment. J Nucl Med 52:690-696

87. Vanderhoek M, Juckett MB, Perlman SB, Nickles RJ, Jeraj R (2011) Early assessment of treatment response in patients with AML using [(18)F]FLT PET imaging. Leuk Res 35:310-316

88. Smyczek-Gargya B, Fersis N, Dittmann H, Vogel U, Reischl G, Machulla HJ, Wallwiener D, Bares R, Dohmen BM (2004) PET with [18F]fluorothymidine for imaging of primary breast cancer: a pilot study. Eur J Nucl Med Mol Imaging 31:720-724

89. Been LB, Elsinga PH, de Vries J, Cobben DC, Jager PL, Hoekstra HJ, Suurmeijer AJ (2006) Positron emission tomography in patients with breast cancer using (18)F-3'-deoxy-3'fluoro-1-thymidine ((18)F-FLT)-a pilot study. Eur J Surg Oncol 32:39-43

90. Pio BS, Park CK, Pietras R, Hsueh WA, Satyamurthy N, Pegram MD, Czernin J, Phelps ME, Silverman DH (2006) Usefulness of $3^{\prime}$-[F-18]fluoro-3'-deoxythymidine with positron emission tomography in predicting breast cancer response to therapy. Mol Imaging Biol 8:36-42

91. Kenny L, Coombes RC, Vigushin DM, Al-Nahhas A, Shousha S, Aboagye EO (2007) Imaging early changes in proliferation at 1 week post chemotherapy: a pilot study in breast cancer patients with $3^{\prime}$-deoxy-3'-[18F]fluorothymidine positron emission tomography. Eur J Nucl Med Mol Imaging 34:13391347

92. Contractor KB, Kenny LM, Stebbing J, Rosso L, Ahmad R, Jacob J, Challapalli A, Turkheimer F, Al-Nahhas A, Sharma R, Coombes RC, Aboagye EO (2011) [18F]-3'Deoxy-3'-fluorothymidine positron emission tomography and breast cancer response to docetaxel. Clin Cancer Res 17:7664-7672

93. Contractor K, Aboagye EO, Jacob J, Challapalli A, Coombes RC, Stebbing J (2012) Monitoring early response to taxane therapy in advanced breast cancer with circulating tumour cells and $[(18) \mathrm{F}] 3^{\prime}$-deoxy-3'-fluorothymidine PET: a pilot study. Biomark Med 6:231-233 
94. Cobben DC, Jager PL, Elsinga PH, Maas B, Suurmeijer AJ, Hoekstra HJ (2003) 3'-18F-fluoro-3'-deoxy-L-thymidine: a new tracer for staging metastatic melanoma? J Nucl Med 44:1927-1932

95. Dittmann H, Dohmen BM, Paulsen F, Eichhorn K, Eschmann SM, Horger M, Wehrmann M, Machulla HJ, Bares R (2003) [18F]FLT PET for diagnosis and staging of thoracic tumours. Eur J Nucl Med Mol Imaging 30:1407-1412

96. Cobben DC, Elsinga PH, Suurmeijer AJ, Vaalburg W, Maas B, Jager PL, Hoekstra HJ (2004) Detection and grading of soft tissue sarcomas of the extremities with (18)F-3'-fluoro- $3^{\prime}$ deoxy-L-thymidine. Clin Cancer Res 10:1685-1690

97. Been LB, Suurmeijer AJ, Elsinga PH, Jager PL, van Ginkel RJ, Hoekstra HJ (2007) 18F-fluorodeoxythymidine PET for evaluating the response to hyperthermic isolated limb perfusion for locally advanced soft-tissue sarcomas. J Nucl Med 48:367-372

98. Buck AK, Herrmann K, Büschenfelde CM, Juweid ME, Bischoff M, Glatting G, Weirich G, Möller P, Wester HJ, Scheidhauer K, Dechow T, Peschel C, Schwaiger M, Reske SN (2008) Imaging bone and soft tissue tumours with the proliferation marker [18F]fluorodeoxythymidine. Clin Cancer Res 14:2970-2977

99. Pfannenberg C, Aschoff P, Dittmann H, Mayer F, Reischl G, von Weyhern C, Kanz L, Claussen CD, Bares R, Hartmann JT (2010) PET/CT with 18F-FLT: does it improve the therapeutic management of metastatic germ cell tumours? J Nucl Med $51: 845-853$

100. Ribas A, Benz MR, Allen-Auerbach MS, Radu C, Chmielowski B, Seja E, Williams JL, Gomez-Navarro J, McCarthy T, Czernin
J (2010) Imaging of CTLA4 blockade-induced cell replication with (18)F-FLT PET in patients with advanced melanoma treated with tremelimumab. J Nucl Med 51:340-346

101. Giammarile F, Billotey C, Lombard-Bohas C, Le Bars D, Bournaud C, Masson S, Walter T, Houzard C, Scoazec JY, Hervieu V, Vuillez JP, Cornu C, Janier M, Borson-Chazot F (2011) 18F-FLT and 18F-FDG positron emission tomography for the imaging of advanced well-differentiated gastro-enteropancreatic endocrine tumours. Nucl Med Commun 32:91-97

102. Richard SD, Bencherif B, Edwards RP, Elishaev E, Krivak TC, Mountz JM, DeLoia JA (2011) Noninvasive assessment of cell proliferation in ovarian cancer using [18F] 3'deoxy-3-fluorothymidine positron emission tomography/computed tomography imaging. Nucl Med Biol 38:485-491

103. Benz MR, Czernin J, Allen-Auerbach MS, Dry SM, Sutthiruangwong P, Spick C, Radu C, Weber WA, Tap WD, Eilber FC (2012) $3^{\prime}$-deoxy-3'-[18F]fluorothymidine positron emission tomography for response assessment in soft tissue sarcoma: a pilot study to correlate imaging findings with tissue thymidine kinase 1 and Ki-67 activity and histopathologic response. Cancer 118:3135-3144

104. Yamane T, Takaoka A, Kita M, Imai Y, Senda M (2012) (18)FFLT PET performs better than (18)F-FDG PET in differentiating malignant uterine corpus tumours from benign leiomyoma. Ann Nucl Med 26:478-484 